\title{
Assessment of $\mu$ Grid Distributed Energy Resource Potential Using DER-CAM and GIS
}

\author{
Principal Authors \\ Jennifer L. Edwards*, Chris Marnay, Emily Bartholomew, \\ Boubékeur Ouaglal, Afzal S. Siddiqui, and Kristina S. H. LaCommare \\ Ernest Orlando Lawrence Berkeley National Laboratory \\ 1 Cyclotron Road, MS 90-4000 \\ Berkeley CA 94720-8061 \\ *Renewable and Appropriate Energy Laboratory \\ University of California, Berkeley \\ 4152 Etcheverry Hall \\ Berkeley CA 94720-1730 \\ jedwards@socrates.berkeley.edu
}

January 2002

The work described in this paper was funded by the Assistant Secretary of Energy Efficiency and Renewable Energy, Office of Power Technologies, Clean Energy Analysis Collaborative of the U.S. Department of Energy under Contract No. DE-AC03-76SF00098. 



\section{Table of Contents}

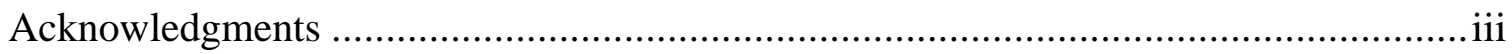

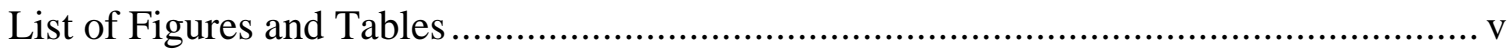

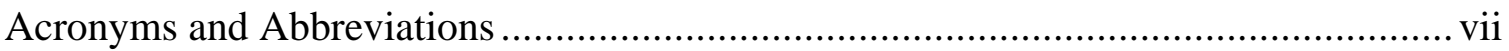

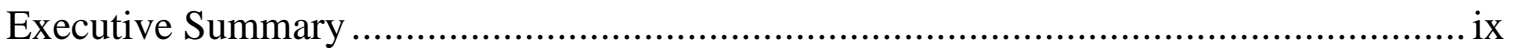

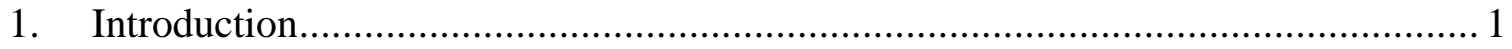

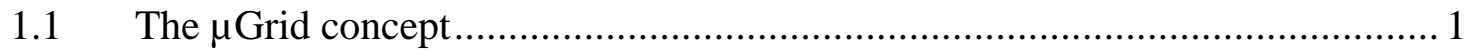

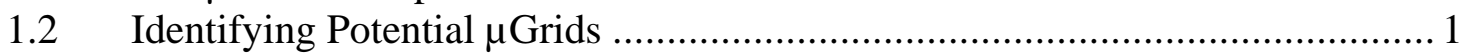

1.3 The Role of Geographic Information Systems.............................................. 2

1.4 Background Work at Berkeley Lab ............................................................. 3

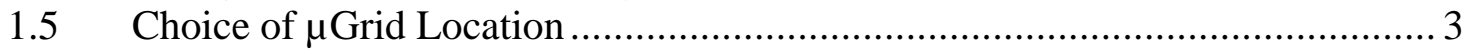

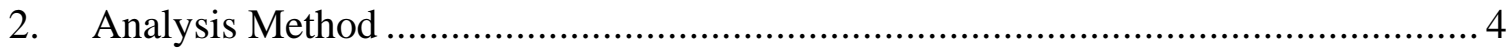

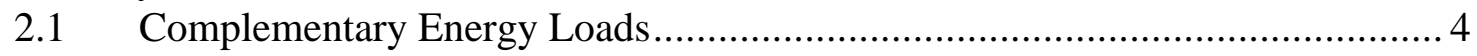

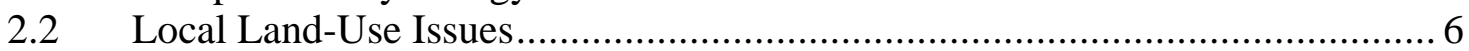

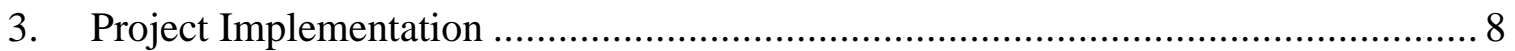

3.1 Summary of Completed Tasks ............................................................... 8

3.2 Additional Data and Assumptions............................................................. 10

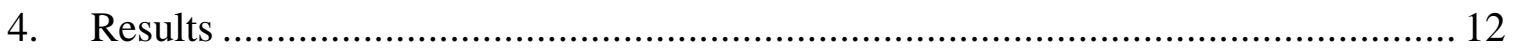

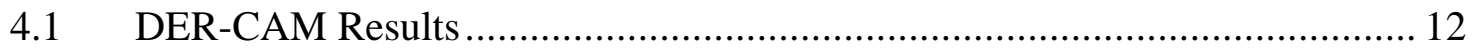

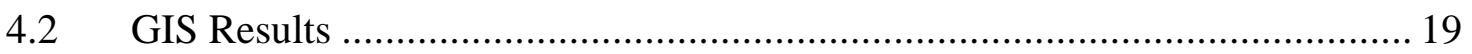

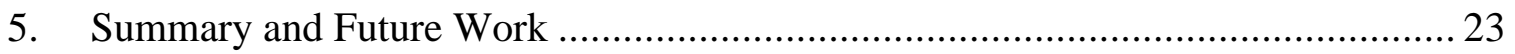

$5.1 \quad$ Summary of Research........................................................................... 23

5.2 Limitations of Data and Analysis Method ..................................................... 23

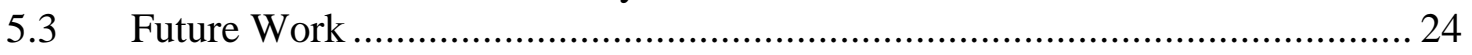

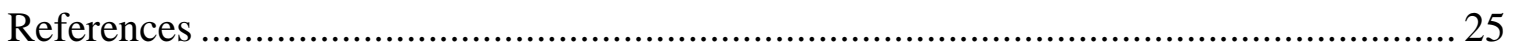

Appendix A San Diego $\mu$ Grid Example Cases ………............................................... 26

Appendix B Preparation and Selection of Energy Load Shapes.................................. 29

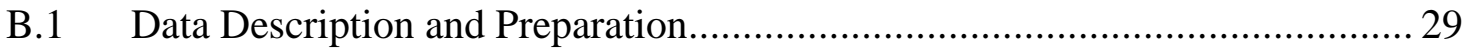

B.2 Additional Estimates......................................................................... 30

B.3 Summary of Energy Data and Sources for Customers in the Small

Commercial/ Residential Area............................................................................... 30

Appendix C DER-CAM Mathematical Model ………............................................... 33

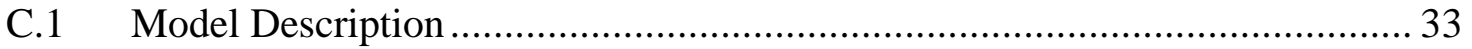




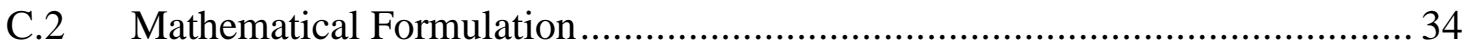

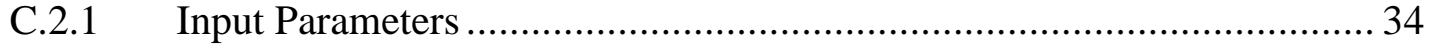

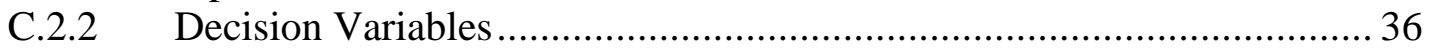

C.2.3 Mathematical Formulation .............................................................. 36

Appendix D DER-CAM Technology Database ............................................... 39

Appendix E San GIS Parcel Layer Metadata...................................................... 40

Appendix F San Diego Zoning Noise Ordinance .............................................. 45

Appendix G San Diego Gas \& Electric Time-of-Use (TOU) Tariff Rates.................. 46 


\section{Acknowledgments}

We would like to thank Owen Bailey and Norman J. Bourassa for their contribution to several important aspects of the modeling for this project. We would also like to thank Nan Wishner for her editing expertise and Timothy E. Lipman for his useful input into this research. In addition, our colleagues Robert H. Lasseter (University of Wisconsin, Madison), Abbas Akhil (Sandia National Laboratory), Ross T. Guttromson (Pacific Northwest National Laboratory), and John Kueck (Oak Ridge National Laboratory) have been instrumental in previous DER collaborations that have helped to shape many of the concepts presented here.

Finally, we would like to thank the Energy Foundation and Tina M. Kaarsberg for her support of this work through the Office of Power Technologies, Clean Energy Analysis Collaborative of the U.S. Department of Energy. 
Assessment of $\mu$ Grid Distributed Energy Potential Using DER-CAM and GIS 


\section{List of Figures and Tables}

Figure ES-1. Methodology to assess suitable DER adoption patterns. ...........................

Figure ES-2. How electricity loads are met in the base-case $\mu$ Grid........................... xii

Figure ES-3. How gas loads are met in the base-case $\mu$ Grid................................... xii

Figure ES-4. Local land-use constraints in the small commercial/residential $\mu$ Grid......xiv

Figure 1. $\mu$ Grid building energy flows. ..............................................................2

Figure 2. GIS data for individual buildings within the small commercial/residential

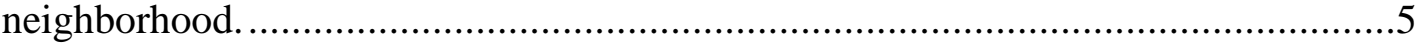

Figure 3. Land-use variation within the small commercial/residential neighborhood.......7

Figure 4. January weekday energy load inputs for the base-case small commercial/

residential $\mu$ Grid. ................................................................................... 12

Figure 5. January weekday energy load inputs for the laundromat.............................13

Figure 6. How January weekday electricity loads are met in the base-case $\mu$ Grid..........15

Figure 7. How January weekday natural gas loads are met in the base-case $\mu$ Grid. ........16

Figure 8 . Installed capacity for the five $\mu$ Grid cases in the small commercial/

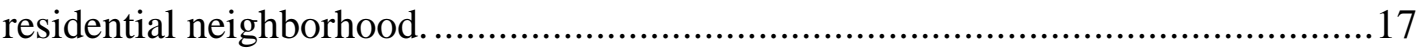

Figure 9. Average cost of electricity and natural gas for the five cases....................... 18

Figure 10. GIS map of individual buildings, classified by energy needs. .....................19

Figure 11. Possible locations for the 500-kW natural gas generator: the hospital,

a large medical office building, and three retail sites. .......................................20

Figure 12. Measured distances between potential generator sites and the hospital........21

Figure 13. Buffer zones at 20, 40, and $60 \mathrm{~m}$ showing noise dissipation over distance and possible interference with local residences............................................22

Figure A-1. Map of buildings in the downtown office/retail area.............................26

Figure A-2. Map of buildings in the small commercial/residential area .......................27

Figure A-3. Map of buildings in the industrial area. ...........................................28

Table 1. Results for the five cases of the small commercial/residential $\mu$ Grid ..............14

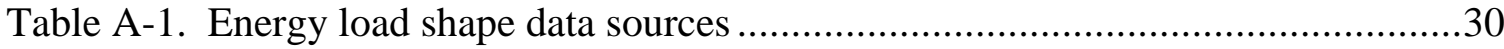

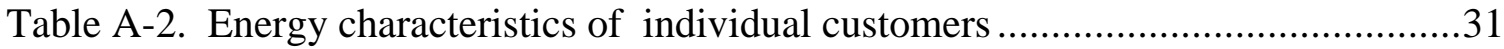

Table A-3. San GIS parcel metadata. .................................................................40

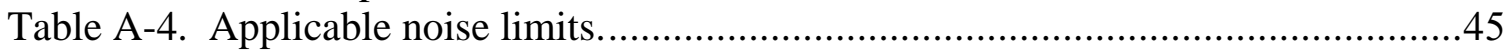

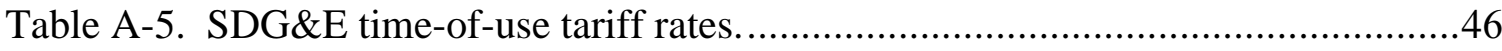


Assessment of $\mu$ Grid Distributed Energy Potential Using DER-CAM and GIS 


\section{Acronyms and Abbreviations}

$\begin{array}{ll}\text { CHP } & \text { combined heat and power } \\ \text { COE } & \text { cost of electricity } \\ \text { dB } & \text { decibel (sound level) } \\ \text { DER } & \text { distributed energy resources } \\ \text { DER-CAM } & \text { Distributed Energy Resource Customer Adoption Model } \\ \text { DG } & \text { distributed generation } \\ \text { GAMS } & \text { General Algebraic Modeling System } \\ \text { GIS } & \text { Geographic Information System(s) } \\ \text { GJ } & \text { gigajoule (energy) } \\ \text { kW } & \text { kilowatt (power) } \\ \text { kWh } & \text { kilowatt hour (energy) } \\ \text { O\&M } & \text { operation and maintenance } \\ \text { SANDAG } & \text { San Diego Association of Governments } \\ \text { SCE } & \text { Southern California Edison } \\ \text { SDG\&E } & \text { San Diego Gas \& Electric } \\ \mu \text { Grid } & \text { microgrid }\end{array}$


Assessment of $\mu$ Grid Distributed Energy Potential Using DER-CAM and GIS 


\section{Executive Summary}

This report outlines a method to assess the local potential for deployment of distributed energy resources (DER), small power-generation installations located close to the point where the energy they produce will be consumed. This methodology combines established economic optimization techniques with a geographic information system (GIS) analysis of local land-use constraints that limit the use of distributed generation (DG) systems. This methodology was developed using an example case in the San Diego area. Our work approaches DER adoption from a customer perspective, based on the premise that future development of DER may take the form of microgrids ( $\mu$ Grids), where multiple neighboring end users are aggregated, and energy loads and generation are jointly managed using standardized "plug and play" power electronics. Previous work in the field of power system planning has focused on the electrical requirements and economic feasibility of incorporating $\mu$ Grids into the current power-supply infrastructure. However, although local restraints such as zoning codes and on-site physical barriers are well-known frustrations in the field of DER, no analysis method has been developed to address them. The need for such a method is the inspiration for this work. By incorporating established DER analysis techniques with a GIS, local spatial constraints on DER can be readily addressed and analyzed. GIS currently plays an essential role in transportation and city infrastructure planning; we propose that it can play a similarly important role in future DER deployment.

The method developed in this project builds on previous work at Ernest Orlando Lawrence Berkeley National Laboratory (Berkeley Lab) that produced the Distributed Energy Resource Customer Adoption Model (DER-CAM). DER-CAM is an economic model that compares distributed technology installation and operation costs to utility rate structures; it determines the optimal, cost-minimizing combinations of generation and CHP technologies for any test customer. DER-CAM provides an economic basis for assessing DG technology adoption patterns within a $\mu$ Grid, and a GIS is used to enhance this basic approach in two primary ways. First, GIS data for existing building patterns in the San Diego area are used to identify neighboring customers that could hypothetically join together to form a $\mu$ Grid. Using GIS data to restrict the customer combinations analyzed in this project to those that are located near each other in an existing city plan ensures that the hypothetical $\mu$ Grid has a realistic basis. Second, a GIS is used to identify local land-use restrictions that may inhibit or prevent installation of economically attractive DER technologies. These land-use restrictions include noise and air quality limits, restrictions on crossing public rights-of-way, the density of buildings and availability of open space to install a generator, physical limitations on the transfer of generator waste heat, and access to high-pressure natural gas lines. By using a combination of DER-CAM and GIS to assess the economic feasibility and land-use compatibility of commercial DG technologies, suitable DER adoption patterns can be identified. Figure ES-1 outlines the methodology developed in this report. 


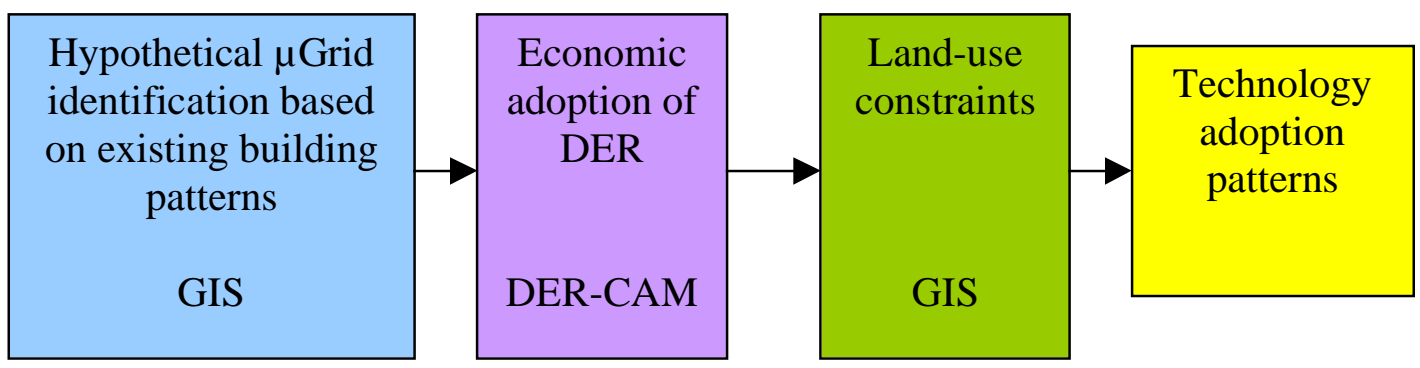

\section{Figure ES-1. Methodology to assess suitable DER technology adoption patterns using DER-CAM and GIS}

This analysis methodology was used to answer three fundamental questions about $\mu$ Grid development:

- Where are adjacent customers with complementary energy loads found, providing an existing basis for $\mu$ Grid development?

- $\quad$ Do individual customers benefit from joining a $\mu$ Grid, or are they better off installing DG independently?

- What types of DER are the best for a specific site? This question has two components: First, which generation technologies are the most economical once CHP benefits have been accounted for, and second, will those technologies be suitable in view of local landuse restrictions?

The first analysis step is to identify potential $\mu$ Grid sites based on the existing distribution of customers with complementary energy loads. Complementary energy loads are used here to describe end users that realize greater economic benefits through the shared use of on-site technology than through independent installations. We assume that these conditions may result in two ways. First, when customers with large electricity demands and small thermal demands can share waste heat from on-site generation with other end users. Second, when two or more customers have peak electricity demands at different times of the day so that an aggregation of their electricity loads results in a higher capacity factor for the installed generation technology. The aggregation of these loads will result in a greater number of $\mathrm{kWh}$ over which to spread the levelized generator cost without requiring that an additional generator be purchased to meet a larger peak.

Beginning with the above assumptions about which customer combinations have complementary energy loads, a GIS was used to locate specific neighborhoods in the San Diego area where these customer combinations exist. Three areas were identified: a small commercial/residential neighborhood with retail shops, residences, and a small hospital; an industrial area with manufacturing facilities, warehouses, and some bars and restaurants; and an area in the downtown financial district with office buildings, retail stores, and fast food restaurants. These three neighborhoods have different zoning classifications, and zoning laws determine the land-use restrictions to which customers in the area are subject. In addition, the zoning designation for an area gives some indication of the energy requirements of a typical customer located in that area. For example, an industrial-zoned customer and a commercialzoned customer are likely to have different energy end-use needs. 
A detailed energy analysis was conducted for the commercial/residential area. This required the construction of a database of energy loads that could be applied to customers at that site, divided into five energy end uses for input into DER-CAM. These five end-use loads are: electricityonly loads such as lighting, computers, and most appliances; hot-water and space-heat loads that can be met with either generator waste heat or direct combustion of natural gas; cooling loads that can be met with either standard compressor chillers or absorption cooling technologies using waste heat; and natural-gas-only loads, such as cooking, that cannot be met with CHP technologies. This database was created primarily using electricity end-use data collected by Southern California Edison (SCE) and natural gas loads simulated by DOE-2 (a building-energy program created at Berkeley Lab), though several additional sources and extrapolations were required. These load shapes are input into DER-CAM along with cost and operating characteristics of commercially available DER technologies, fuel costs, and utility electricity tariff rates. DER-CAM then outputs the optimal generator supply schedule for a given customer.

The DER-CAM results for five $\mu$ Grid customer combinations within the small commercial/residential neighborhood were analyzed to determine the advantages of complementary energy loads. First, the entire $\mu$ Grid was compiled to establish a base-case scenario and to reflect the existing land-use patterns at the site. Two variations on this base case were constructed: doubling the energy loads of all the customers in the $\mu$ Grid to reveal potential economies of scale, and disconnecting the residential customers. Next, two customers, the hospital and a laundromat, were analyzed individually to address the question of whether or not it would be beneficial for certain customers to install DG independently. DER-CAM results for these five cases show the DER technologies chosen on an economic basis to supply power and heat to the $\mu$ Grid and the hours at which these technologies operate. In all five scenarios, different combinations of natural gas reciprocating engines were chosen by DER-CAM, ranging in size from $25 \mathrm{~kW}$ to $500 \mathrm{~kW}$. These generators operate throughout the day and are supplemented by purchased electricity during late-night and early-morning hours when utility time-of-use (TOU) tariff rates are lowest. All three $\mu$ Grid scenarios displaced 81 percent of their annual gas load through CHP. The laundromat and the hospital supplied 36 percent and 84 percent of their annual gas load with CHP, respectively. Figures ES-2 and ES-3 below show how the base-case $\mu$ Grid energy loads are met with purchased and on-site generation and CHP. 


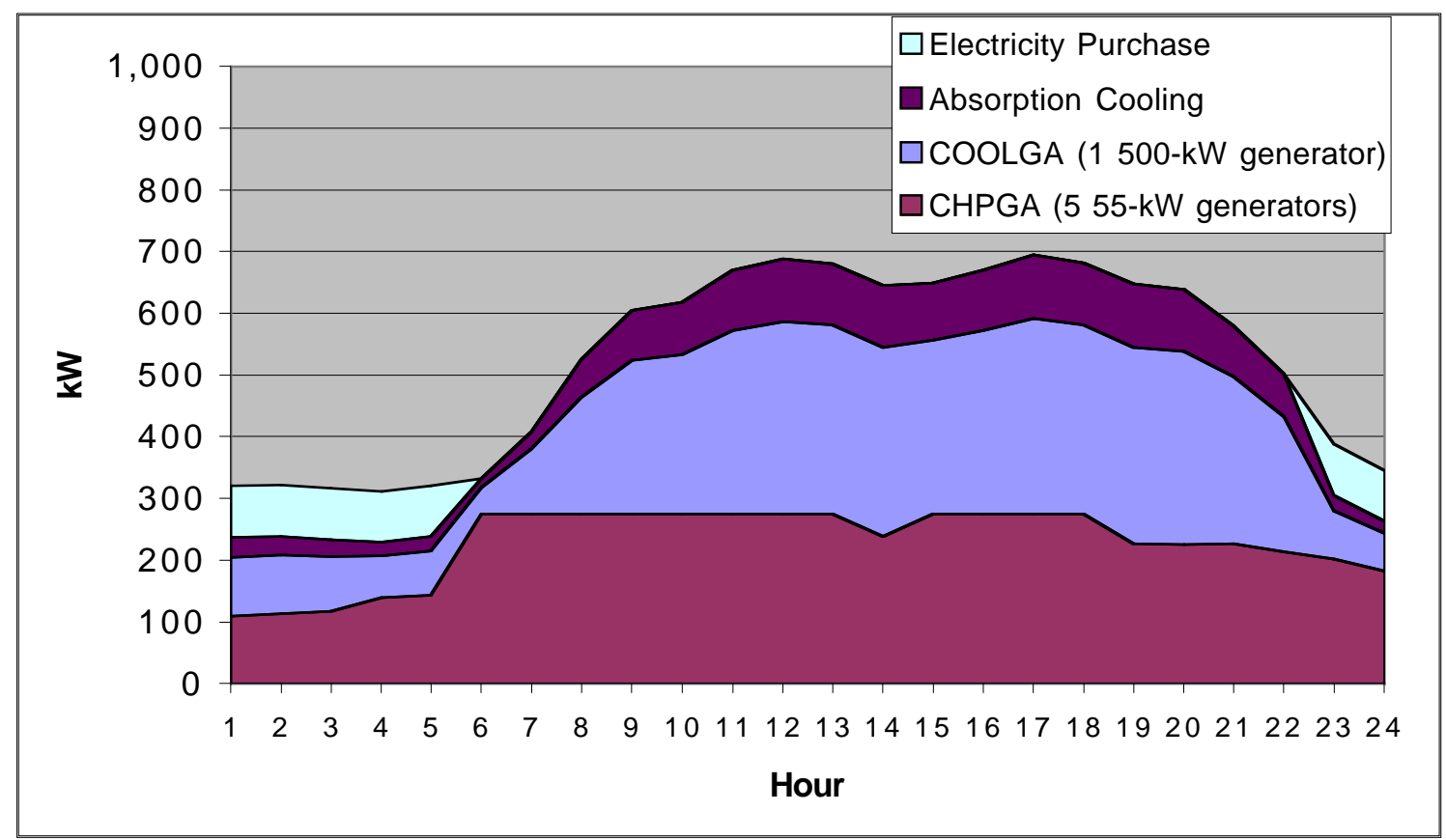

Figure ES-2. How electricity loads are met in the base-case $\mu$ Grid. The absorption cooling band represents an electricity demand reduction as air-conditioning loads are displaced by on-site CHP cooling technologies.

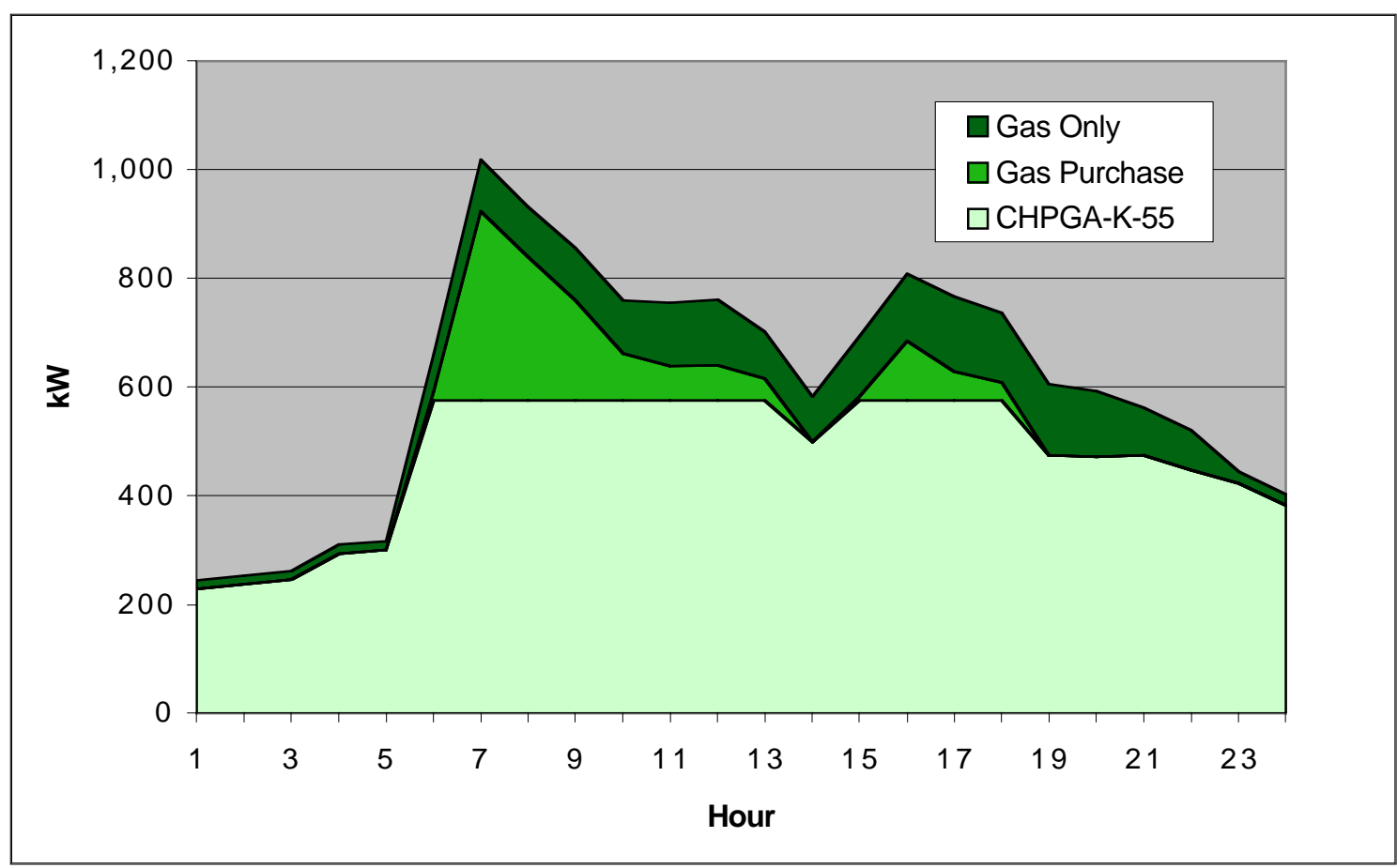

Figure ES-3. How gas loads are met in the base-case $\mu$ Grid. The CHP output shown in the lowest band is supplied by five $55-\mathrm{kW}$ generators. 
A cost comparison of the three $\mu$ Grid cases showed no variation between the base-case $\mu$ Grid and the double-size $\mu \mathrm{Grid}$, both of which had an average cost of electricity (COE) of $6.8 \notin / \mathrm{kWh}$. The COE for the no-residence case was slightly higher at $8 \notin / \mathrm{kWh}$, because the technology investment is the same as for the base-case $\mu \mathrm{Grid}$, but there are fewer kWh over which to spread the levelized generator costs. This demonstrates the benefits of complementary electricity loads, because residential electricity use is highest in the early evening, and the peak use of commercial and office customers is in the afternoon. The laundromat saves an average of $0.7 \notin / \mathrm{kWh}$ by purchasing electricity through the $\mu \mathrm{Grid}$. The laundromat is an interesting case because of its high ratio of heat to electricity demand. The high heat demand suggests a large economic benefit would result from the use of CHP. On an individual basis, however, the low electricity load prevents the customer from benefiting from CHP because the generator electrical output is not large enough to produce adequate waste heat. This result demonstrates another benefit of complementary energy loads, as the laundromat realizes greater economic benefits by sharing electricity and waste heat from larger generators with other customers in a $\mu$ Grid. Results show that the average COE is lowest for the hospital case at $4.9 \notin / \mathrm{kWh}$, in part because the hospital has the highest annual load factor of 69 percent. This low cost does not provide an immediate economic incentive for the hospital to connect to the $\mu \mathrm{Grid}$. These two individual customer cases demonstrate the large variability in the economics of DER adoption, which depends on the size of the customer and the ratio and overlap of electricity and heat loads as a determinant of potential CHP benefits.

Once the hypothetical $\mu$ Grid technology choices and operating schedules were identified by DER-CAM, a GIS was used to assess three local land-use constraints. First, the availability of open space for a generator site was determined by calculating the generator footprint and identifying the building sites large enough to accommodate the generator. Five possible sites were identified at this stage: the hospital, three large retail sites, and a medical office building. Second, physical constraints on CHP heat transfer were examined by measuring the distance between these five identified sites and the hospital, the largest heat sink in the $\mu$ Grid. The heattransfer distances were shown to be relatively large, ranging from $220 \mathrm{~m}$ to $280 \mathrm{~m}$, suggesting that insulation upgrades may be an important economic consideration for this $\mu$ Grid. The third constraint analyzed was the effect of generator noise on local buildings. The distance at which the noise output of the largest generator is reduced to the level allowed by local zoning codes was calculated to be $60 \mathrm{~m}$, and a buffer zone was placed at this distance from each of the possible generator sites. Local buildings that would be negatively affected by noise can be identified from their overlap with this buffer zone. The results of this analysis show that six or seven residences would be affected by noise at each possible generator site.

The figure below shows the GIS results for the hospital and one of the retail sites in the small commercial/ residential base case $\mu \mathrm{Grid}$. The buildings in yellow are the sites large enough to accommodate a generator. The gray bands represent the noise buffer for each site at a distance of $60 \mathrm{~m}$. The figure shows the local residences that fall within this buffer and would therefore be exposed to noise levels exceeding those allowed by zoning laws. In addition, the red arrow shows the heat-transfer distance from the retail site to the hospital. 


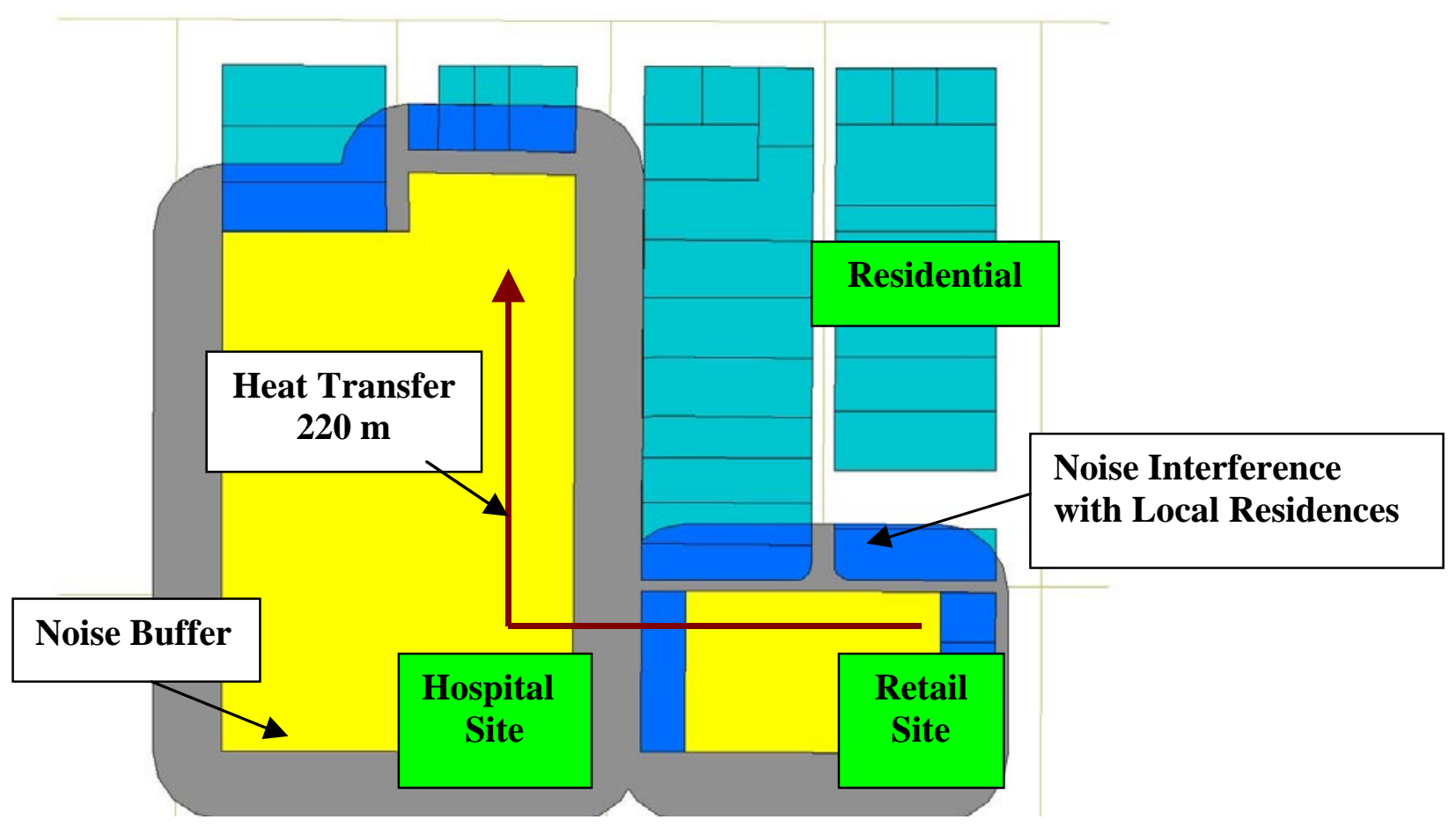

Figure ES-4. Local land-use constraints in the small commercial/ residential $\mu$ Grid.

The results from the GIS analysis described above show the optimal sites for the technologies chosen on an economic basis by DER-CAM, and reveal some of the inherent difficulties or possible advantages DG might encounter as a result of local land-use patterns. The GIS analysis process reveals that certain technologies might have to be eliminated from consideration based on overall noise restrictions, and that other technologies would be suitable if additional requirements, such as heat-transfer upgrades, were met. The GIS analysis methods used for these three example constraints can easily be extrapolated to include additional local barriers.

This work is intended to be an exploratory first step toward an integration of GIS analysis methods with DER-CAM to produce an automated process of $\mu$ Grid identification. The focus of this report is on the GIS portion of the analysis although several important economic questions are also addressed. The fundamental future barriers to DER adoption will most likely be economic, but it is worthwhile to take geographic constraints into account at this stage of development, and to evaluate methods of assessing them. With the compilation of more complete databases of small-scale land-use information, GIS may prove to be an important tool in the analysis of DER technology potential. 


\section{Introduction}

This report describes the use of a Geographic Information System (GIS) to identify physical barriers, such as local land-use and zoning constraints, to the deployment of distributed energy resources (DER). A method to simulate and identify potential locations of on-site power generation was developed and applied to some example sites in San Diego, California.

\subsection{The $\mu$ Grid concept}

Non-utility distributed generation (DG) development is typically thought of as a singlecustomer/single-generator problem. DG investment is made by one end user to meet its own specific energy needs, e.g., for back-up generation, high power quality, or use of combined heat and power (CHP). Efforts to create standardized interconnection rules for DER usually start from the premise that DG is added in discreet, single units. However, DG could be made more attractive through the development of microgrids ( $\mu$ Grids), in which multiple neighboring end users are aggregated, and energy loads and generation are jointly managed using standardized "plug and play" control technologies. ${ }^{1}$ DG systems that are planned around $\mu$ Grids have several advantages over systems based on single customer-generators. First, combining the electricity demand of several small end-users is a flexible way of allowing customers to take advantage of economies of scale. Second, certain customer types may have complementary energy needs and can increase efficiency through mutual use of on-site CHP. One example might be a building with large electricity needs but a small heat load located next to a building with a high heat demand, so both customers can take advantage of the electrical and CHP output of the same generator. Identifying and simulating such potentially compatible loads is one important element of this study. ${ }^{2}$

The $\mu$ Grid concept is based on the belief that power electronics can be developed to allow multiple small generators and loads to function as a unit in both grid-parallel and "islanded" modes. That is, the $\mu$ Grid could function as a single legitimate entity in relation to the utility grid. From the customer's point of view, the $\mu$ Grid could deliver minimum-cost energy services to end users because a central $\mu$ Grid control station could regulate the $\mu$ Grid's energy purchase, self-generation, and energy sale schedules so that costs are minimized.

\section{$1.2 \quad$ Identifying Potential $\mu$ Grids}

Optimal combinations of building loads can be found through analysis of yearly energy load shapes for different customer types. For the purposes of this project, energy end uses are categorized into five types (as shown in Figure 1): electricity-only loads such as lighting; cooling loads that can be met with either standard compressor chillers or absorption cooling technologies using waste heat; hot-water and space-heat loads that can be met either with

\footnotetext{
${ }^{1}$ For more information on $\mu$ Grids see Marnay et al., 2001.

${ }^{2}$ A third potential benefit of $\mu$ Grids, that is not addressed in this study, derives from the possibility that electricity reliability and quality might be locally tailored to the requirements of the heterogeneous end uses of on-site facilities. By locally supporting sensitive loads, such as computer or control equipment, the $\mu$ Grid could function adequately with relatively low levels of grid-supplied power.
} 
generator waste heat or combustion of natural gas directly; and natural-gas-only loads, such as cooking, that cannot be met with CHP technologies.

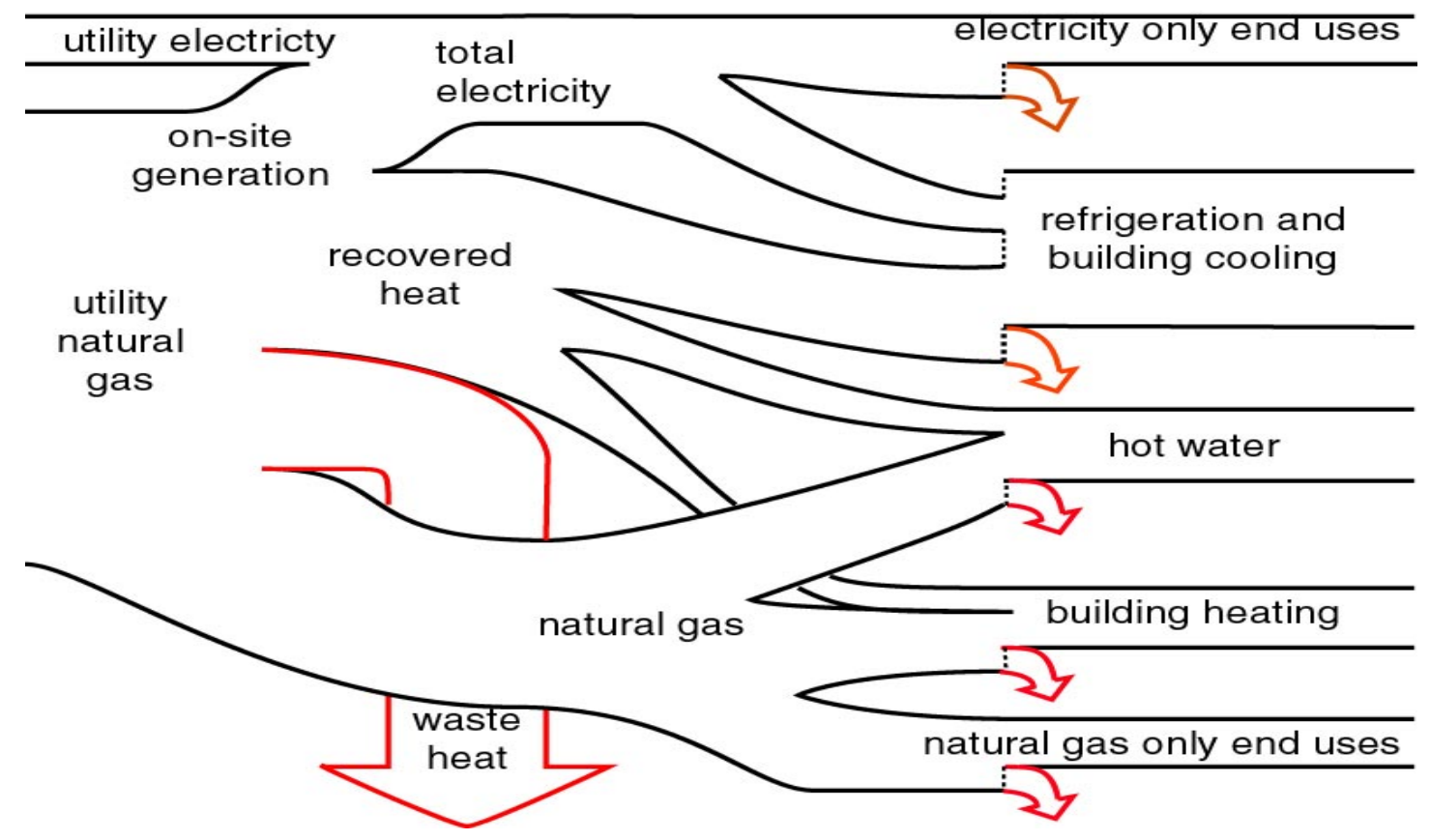

Figure 1. $\mu$ Grid Building Energy Flows

Finding optimal on-site generating adoption requires hourly load profiles for energy use by the end-use categories. These end-use load shapes can be analyzed using the Distributed Energy Resource Customer Adoption Model (DER-CAM) ${ }^{3}$ developed by Ernest Orlando Lawrence Berkeley Lab (Berkeley Lab). DER-CAM is an economic model that compares the installation and operation costs of commercially available DER technologies to utility rate structures; DERCAM's output is the optimal cost-minimizing supply schedule of generation and CHP technologies for a given customer. Equipment options include natural gas reciprocating engines and microturbines with CHP retrofits, solar panels, wind turbines, and fuel cells. Altering the DER-CAM energy load inputs to correspond to different test $\mu$ Grids shows which building combinations benefit economically from shared use of on-site energy generation.

\subsection{The Role of Geographic Information Systems}

Because distributed power generation is by definition located near the end user, the planning and siting of DG units must take into account not only the electrical and economic requirements of the system but also key deployment constraints at the site. These constraints include land-use restrictions, such as local zoning and noise ordinances, that affect the use of certain DG technologies but cannot be analyzed based on economics alone. In addition, although theoretical ideal building combinations may be found by DER-CAM analysis, the buildings that DER-

\footnotetext{
${ }^{3}$ For more information see Appendix C and Marnay et al., 2000 and 2001, Rubio et al., 2001, and Siddiqui et al., 2001.
} 
CAM identifies may not be located near each other in typical city plans. These land-use and locational constraints to $\mu$ Grid planning are inherently spatial and can readily be analyzed using a GIS. By incorporating an analysis of $\mu$ Grid distributed technology adoption into a GIS, one can identify crucial spatial issues influencing $\mu$ Grid deployment. Furthermore, by using GIS land-use data that show building layouts in existing neighborhoods as the basis for choosing $\mu$ Grid customer combinations, the theoretical $\mu$ Grid concept is applied in a real-world context. Therefore, the role of GIS analysis in simulation of DER adoption by $\mu$ Grids has two components: first, to use existing city plans as the basis for choosing $\mu$ Grid customer combinations, and second, to show how spatial constraints that are not revealed through pure economic analysis can influence DER adoption.

\subsection{Background Work at Berkeley Lab}

The work described in this report has been completed with fiscal year 2001 funding from the Office of Power Technologies (OPT) Analysis Collaborative. The intent of this work is to explore analysis techniques that can take into account localized restrictions on DER deployment that are not readily incorporated into traditional economic analyses, such as the method embodied in the Energy Information Administration's National Energy Modeling System (NEMS). Prior Berkeley Lab work has shown that GIS can be a powerful tool for addressing spatially defined limitations in energy research. ${ }^{4}$ In the exploratory work described here, economic analysis tools (primarily DER-CAM) developed prior to this project (with funding from the Transmission Reliability Office of OPT and the California Energy Commission) are supplemented by a GIS as a step toward a fully integrated model of DER adoption that includes localized constraints along with economic considerations.

\subsection{Choice of $\mu$ Grid Location}

Although the goal of this work is to develop a general analysis approach for assessment of DER adoption potential, the practical starting point is to study an example case. This project looks specifically at $\mu$ Grid development potential in San Diego CA. Several factors make San Diego an interesting test case for customer-adopted distributed generation:

- $\quad$ Customers served by San Diego Gas and Electric (SDG\&E) received much attention during the summer of 2000 because SDG\&E had completed the process of deregulation mandated by the state and was able to pass on that summer's high market electricity rates to customers. This situation motivated customers and policy makers to consider possible alternatives to the current electricity supply structure, such as distributed generation and real-time pricing to allow customer demand to respond directly to market fluctuations.

- $\quad$ San Diego is a transmission-constrained area with rapid load growth where sizeable transmission or generation construction is unlikely, so it is an attractive location for DER.

- San Diego has collected a wealth of publicly available GIS data for land-use patterns, roads, climate variation, environmentally sensitive areas, and other information relevant to a local analysis of distributed generation deployment.

\footnotetext{
${ }^{4}$ See Marnay et al., 1997 and Segzen, et al., 1998.
} 


\section{Analysis Method}

This section describes the general analysis approach used to incorporate a GIS into a simulation of DER adoption for the San Diego example case. Limitations on time, budget, and data mean that we performed only some of the possible analysis steps in this study. The following section on completed tasks describes in detail the actual implementation achieved in this study.

\subsection{Complementary Energy Loads}

The first step in this analysis is to identify example $\mu$ Grid customer combinations. These $\mu$ Grid customer combinations were chosen based on their proximity to each other in an existing city plan and their potential to have complementary energy loads with neighboring customers. Complementary energy loads refer to customers that realize greater economic benefits through the shared use of on-site generation than through individual installations.

GIS data for existing land-use patterns and building locations were used to identify customers located near each other. One database containing this information has been compiled through SanGIS, a Joint Powers Agreement between the city and county of San Diego whose purpose is "to maintain and promote the use of a regional geographic data warehouse for the San Diego area." Data from SanGIS show individual land parcels classified by building type, e.g., singlefamily residence, community shopping center, or medical office. Figure 2 shows an example of these data for one of the areas identified in this study.

\footnotetext{
${ }^{5}$ For more information see http://www.sangis.org.
} 


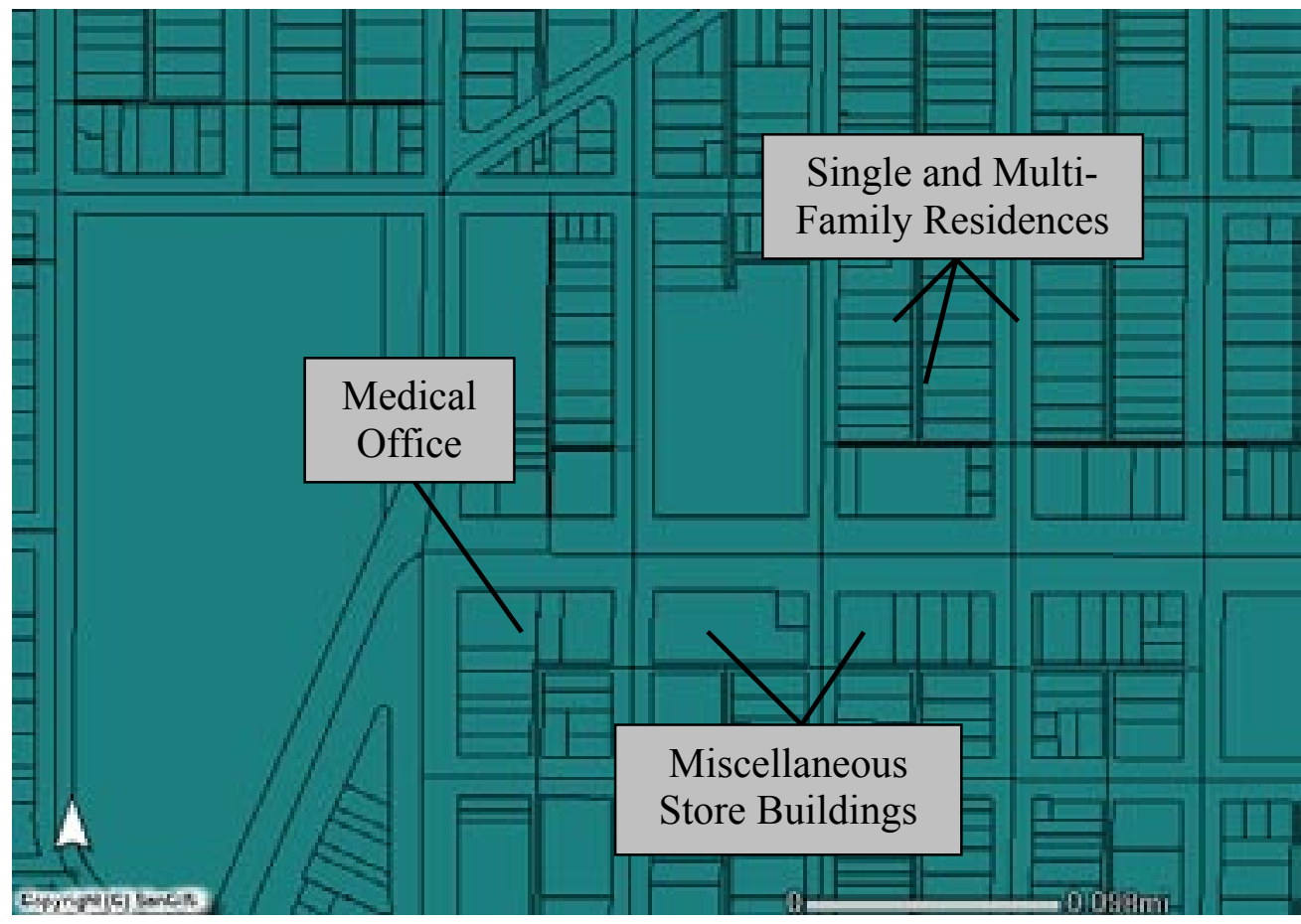

\section{Figure 2. GIS data for individual buildings within the small commercial/residential neighborhood.}

The next step in identifying potential $\mu$ Grid customer combinations is to ascertain the end-use energy loads of each individual customer type as a determinant of their potential role in a $\mu \mathrm{Grid}$. By assigning energy end-use load data to a map of individual customers, the energy intensity and hours of use appropriate to a specific customer type can be spatially analyzed, and customer combinations with complementary energy loads can be identified based on their proximity to each other.

A key consideration in identifying complementary energy loads is related to a finding from previous work with DER-CAM, which showed that the economics of distributed generation correspond closely to a customer's electricity load factor. ${ }^{6}$ The load factor is a measure of the total electricity consumed relative to the electricity that would have been consumed if the peak load were sustained throughout a given time period. A high load factor implies that electricity load varies little over time, and a load factor of 100 percent represents a constant load throughout the time period. A high load factor would correspond to a high capacity factor for installed generation technology, providing a large economic incentive for on-site generation. Therefore, complementary electrical loads within a $\mu$ Grid are buildings whose hours of peak usage vary from each other throughout the day. For example, an office building and a sit-down restaurant have complementary electrical loads because the office tends to have peak usage in the afternoon, and the restaurant has peak usage during evenings and weekends.

\footnotetext{
${ }^{6}$ See Marnay et al., 2001
} 
A second type of complementary building load allows customers with high electricity usage but low heat loads to share waste heat with neighboring customers that have high thermal demands. One example would be a neighborhood with retail stores or office buildings that have high daytime electrical usage rates located near a building with a high daytime heat sink, such as a hospital. A GIS analysis of the proximity of buildings with complementary heat and power loads is especially important, because of the relatively high losses associated with heat distribution.

Although the work conducted for this project focuses on the energy benefits of certain customer combinations, it is also important to consider the role of individual customers with exceptional power quality or reliability needs. Siting generation or storage close to these sensitive loads is likely to provide considerable benefits to the $\mu \mathrm{Grid}$. A spatial analysis that identifies sensitive loads could be incorporated into the identification of complementary energy loads, to address two potential benefits of the $\mu$ Grid simultaneously.

\subsection{Local Land-Use Issues}

Once energy loads have been quantified and the economically attractive distributed technology combinations chosen by DER-CAM, other obstacles or advantages to siting the chosen technologies in a specific location can be identified. This second analysis step is based on zoning classifications of the specific $\mu$ Grid site in question. GIS data from the San Diego Association of Governments (SanDAG) classify regions of the county based on general land-use patterns, such as commercial, industrial, or single- or multi-family residential districts. These data complement the individual building data from SanGIS and contain the zoning patterns of the county, indicating regions of distinct building or noise ordinances. ${ }^{7}$ Figure 3 shows an example of these zoning data from SanDAG for the same neighborhood represented in Figure 2 above.

\footnotetext{
${ }^{7}$ For an example of San Diego zoning ordinances, see Appendix F.
} 


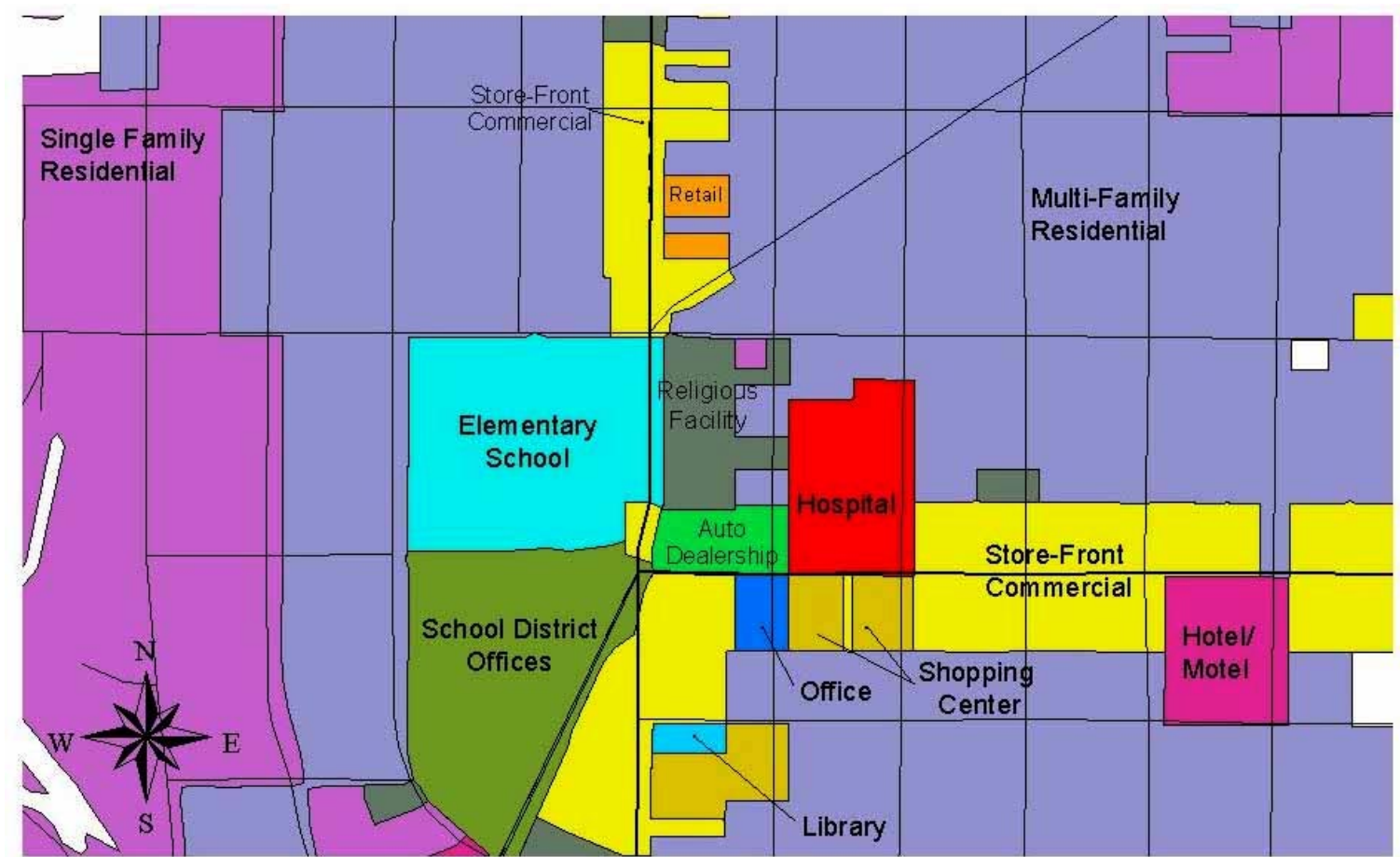

Figure 3. Land-use variation within the small commercial/residential neighborhood. Zoning boundaries as well as large individual buildings are shown.

Once zoning patterns for a particular neighborhood are known, land-use restrictions applicable to distributed generation can be referenced in city or county zoning ordinances. These include noise or air quality limits, useable open space requirements, and restrictions on crossing public rights-of-way. Other equally important siting constraints that are not related directly to zoning ordinances are the density of buildings and the availability of open space to install a generator, the physical limitations on the transfer of generator waste heat, the shading of photovoltaic systems by tall buildings, access to high-pressure gas lines, and weaknesses of the utility distribution system that may provide added incentive for installing DG. All of the above constraints can be identified and quantified, if applicable, using a GIS. 


\section{Project Implementation}

This section describes the specific steps in the analysis of $\mu$ Grid potential in San Diego. This research was conducted from February through December 2001.

\subsection{Summary of Completed Tasks}

The following tasks were completed:

- An initial analysis of San Diego County was conducted using GIS zoning and land-use data from SANDAG (as shown in Figure 3 above) to find three example areas with different building combinations and land-use characteristics in which to place a hypothetical $\mu \mathrm{Grid}$. At this stage of the analysis, the emphasis was on finding the following: neighborhoods containing buildings with large thermal needs such as hospitals or laundromats, customers with late-night or 24 hour loads such as bakeries or certain industries, regions of industrial zoning, and customers with sensitive loads requiring high reliability. Because of the limits of the SANDAG database, some of these characteristics could not be identified, so best-guess estimates of building type were used. The three areas below were chosen because they represent neighborhoods with different zoning, which determines the land-use restrictions that customers in the area are subject to. In addition, the zoning designation for an area gives an indication of the energy requirements of a customer located there.

_ Small Commercial/Residential: This neighborhood contains a mix of single-family and multiple-family housing units, small retail sites, a small hospital, and some office sites including a medical office building.

_ Industrial: This area has no residences and contains industrial-zoned businesses such as auto repair shops, a bottling plant, a construction supply firm, and warehouses. In addition there are small office buildings, some bars and restaurants, and a telephone exchange that is classified as a sensitive load.

_ Downtown Office/Retail: This area contains large office buildings and several retail stores, a large hotel, and several sit-down and fast food restaurants.

- $\quad$ Once three regions with varying characteristics were identified, GIS data for individual land parcels in each neighborhood were purchased from the SanGIS database (see Figure 2 and Appendix E).

- In some instances, parcel metadata from SanGIS (which describe site characteristics other than a parcel's geographic location) were not sufficient to determine the specific customer type at each location, which is the key determinant of energy end-use loads in this project. For example, a copy store and a 24-hour mini-mart are both classified as miscellaneous store buildings, but they have very different energy-use patterns. Therefore, the SanGIS database was supplemented by in-person surveys of the San Diego sites. Information was collected on the specific commercial and industrial uses of each site as well as individual customer locations within strip malls that are classified as single parcels. 
- A detailed energy-use analysis was conducted for the small commercial/residential example $\mu \mathrm{Grid}$. The area contained approximately 25 commercial customers and 40 residences. These customers were divided into 10 building types based on distinct energy needs. Energy load-shape data representative of these 10 building types were collected from a variety of sources and compiled in an Excel database. In general, energy-load data are proprietary and difficult to obtain. Additional difficulties were encountered because distinct end-use metered load data were needed for electricity and natural gas, but natural gas is rarely metered on an hourly use basis. The primary source of electricity load data is a database collected by Southern California Edison (SCE) of 53 commercial customers in the SCE service territory. Daily load shapes were combined into monthly week- and weekend-day averages, and electricity use attributable to cooling was extracted as a distinct load profile. Some estimations and manipulations to measured data were required where there were missing data or where customer types did not correspond to any available measured data. In the latter instances, load shapes were constructed from measured data of applicable end uses (such as lighting) and estimated additional energy use by appliances characteristic of that customer type (such as washers and dryers for the laundromat). For building types with unusual hours of operation (such as 24-hour markets or late-night stores), the early evening loads of measured businesses were extrapolated to include late evening hours. Natural gas load data were created using DOE-2, a building energy simulation program developed at Berkeley Lab. The correct floor area for each building was input to DOE-2, end-use loads appropriate to each customer type were selected, and the program was run. The output data were then averaged into the same monthly format as the electrical loads. It should be emphasized that the energy data used do not represent actual usage by any of the customers in this analysis; these data were obtained from commercial databases and other metered customers in the southern California area. For more information on preparation of building load shapes, see Appendix B.

- $\quad$ Five energy end-use loads are of importance to this study, as mentioned above. These are cooling loads, electricity-only loads, hot-water loads, space-heat loads, and gas-only loads. These five end-use load sets were collected for each of the 10 building types for a total of 50 energy load sets. ${ }^{8}$ The Excel database contains energy end-use data in units of $\mathrm{W} / \mathrm{m}^{2}$. Final energy loads were obtained by inputting the total area for a given building type as calculated by a GIS, using the approximation that each building takes up 75 percent of the total property area. This is a straightforward and flexible method of calculating energy loads for different building combinations within the $\mu$ Grid.

- $\quad$ Energy load data were compiled for five different cases of the small commercial/residential $\mu$ Grid and run through the DER-CAM model. These five cases are:

_ Base-case $\mu$ Grid: The entire $\mu$ Grid was compiled with all 10 building types and their actual floor area to reflect the existing land use at the site.

_ Double-size $\mu$ Grid: This case entailed doubling the size of all the buildings in the $\mu \mathrm{Grid}$ to reveal potential economies of scale.

\footnotetext{
${ }^{8}$ A single load set contains two representative day types (weekday and weekend) for each month of the year.
} 
- No-residences $\mu$ Grid: This case eliminated the residential buildings from the $\mu$ Grid because of the different rate structures of residential customers and the potential complication of aggregating and retrofitting a large number of small residences.

- Hospital and laundromat cases: These two customers were analyzed individually to address the question of whether or not it would be beneficial for certain customers, especially those with high heat loads, to install DG independently.

- $\quad$ DER-CAM analysis was done for each of these cases under two different energypurchase scenarios: the SDG\&E time-of-use (TOU) tariff rate ${ }^{9}$ and a do-nothing scenario where no DG is installed. These results are discussed below in Section 4.1.

- Next, a limited GIS analysis of local land-use constraints was conducted. DER-CAM results showing the distributed technologies that are economically appropriate for the $\mu$ Grid example were incorporated into a GIS and overlaid with a zoning map of the neighborhood. The resulting map reveals areas of conflict between the DG technology chosen by DER-CAM and local zoning requirements. Three land-use constraints were considered: available space for generator siting, physical constraints on CHP heat transfer, and the effect of generator noise on local noise-sensitive buildings. First, the footprint of the DG technologies chosen by DER-CAM was calculated and compared with a GIS map of individual buildings. A building was assumed to be large enough to house a generator if the generator footprint was less than 1 percent of total building space. From these available sites, distance measurements were made to the farthest buildings and to the buildings with the highest heat sinks, and approximate heat-transfer losses were calculated. Then, generator noise levels at equal distance intervals were calculated based on generator specifications (which give noise level at a single distance) and the assumption that generator noise would dissipate as it does for a single point source. ${ }^{10}$ Buffer zones were placed around the potential generator sites at these distance intervals to determine whether noise interference would be a deterring factor for sensitive buildings such as the hospital and local residences. The purpose of this portion of the analysis is not to quantify these issues from a technical or engineering standpoint but to determine what the general magnitude and effect of land-use constraints would be on neighborhoods with similar development patterns and to exemplify the use of a GIS to solve such problems. Results for the GIS portion of this analysis are discussed below in section 4.2 .

\subsection{Additional Data and Assumptions}

The following cost assumptions and data sources were used in addition to those described above:

\footnotetext{
${ }^{9}$ See Appendix G for SDG\&E tariff rates.

${ }^{10}$ Starting from the definition of decibel level, $\mathrm{dB}=10 \log \left(\mathrm{I} / \mathrm{I}_{0}\right)$ where $\mathrm{I}=\mathrm{P} / 4 \pi \mathrm{r}^{2}, \mathrm{P}$ is the power in the sound wave, and $\mathrm{I}_{0}$ is a constant reference intensity of $10^{-12} \mathrm{~W} / \mathrm{m}^{2}$, the difference in decibel level between two points located at different distances from a point noise source is derived to be $\mathrm{dB}_{1}-\mathrm{dB}_{2}=10 \log \left(\mathrm{r}_{2} / \mathrm{r}_{1}\right)^{2}$ where $\mathrm{r}$ is the distance from the point source.
} 
- Cost and technology data for several commercially available distributed generation technologies were used for input to DER-CAM. These data were collected primarily from manufacturers or retailers and include technology lifetime, variable and fixed operating costs, generator heat rates, and emission output rates of $\mathrm{NO}_{\mathrm{X}}$ and $\mathrm{PM}$. Most of these are year 2000 values, which is when the data were collected. A table summarizing these technology data is included in Appendix D.

- $\quad$ The cost of purchasing electricity from the utility is calculated from SDG\&E year 2000 tariff rates. A table of these tariff rates is included in Appendix G. In addition to these standard tariff rates, customers are assumed to pay a distribution service charge of $\$ 0.036 / \mathrm{kWh}$ on electricity purchased from the utility.

- $\quad$ The cost of natural gas is assumed to be $\$ 8.66 / \mathrm{GJ}$.

- The interest rate on technology investments is assumed to be 7.5 percent. 


\section{Results}

\subsection{DER-CAM Results}

In the small commercial/residential example neighborhood, five building combinations were analyzed as discussed above in section 3.1. These five cases are meant to illustrate the potential advantages of complementary energy loads in $\mu$ Grid planning.

Figure 4 below shows the five January weekday energy-load inputs for the base-case small commercial/residential $\mu \mathrm{Grid}$, which represents all 10 building types at the site and their existing floor area as measured by a GIS. The space-heat, hot-water, and cooling loads are met through the use of waste heat when it is available, but the electricity-only load must be met with on-site or purchased electricity, and the gas-only load must be met by purchased natural gas. Figure 4 shows an electricity load factor of 75 percent for this January day; the highest peak electricity use for this $\mu$ Grid is $886 \mathrm{~kW}$ on a July weekday.

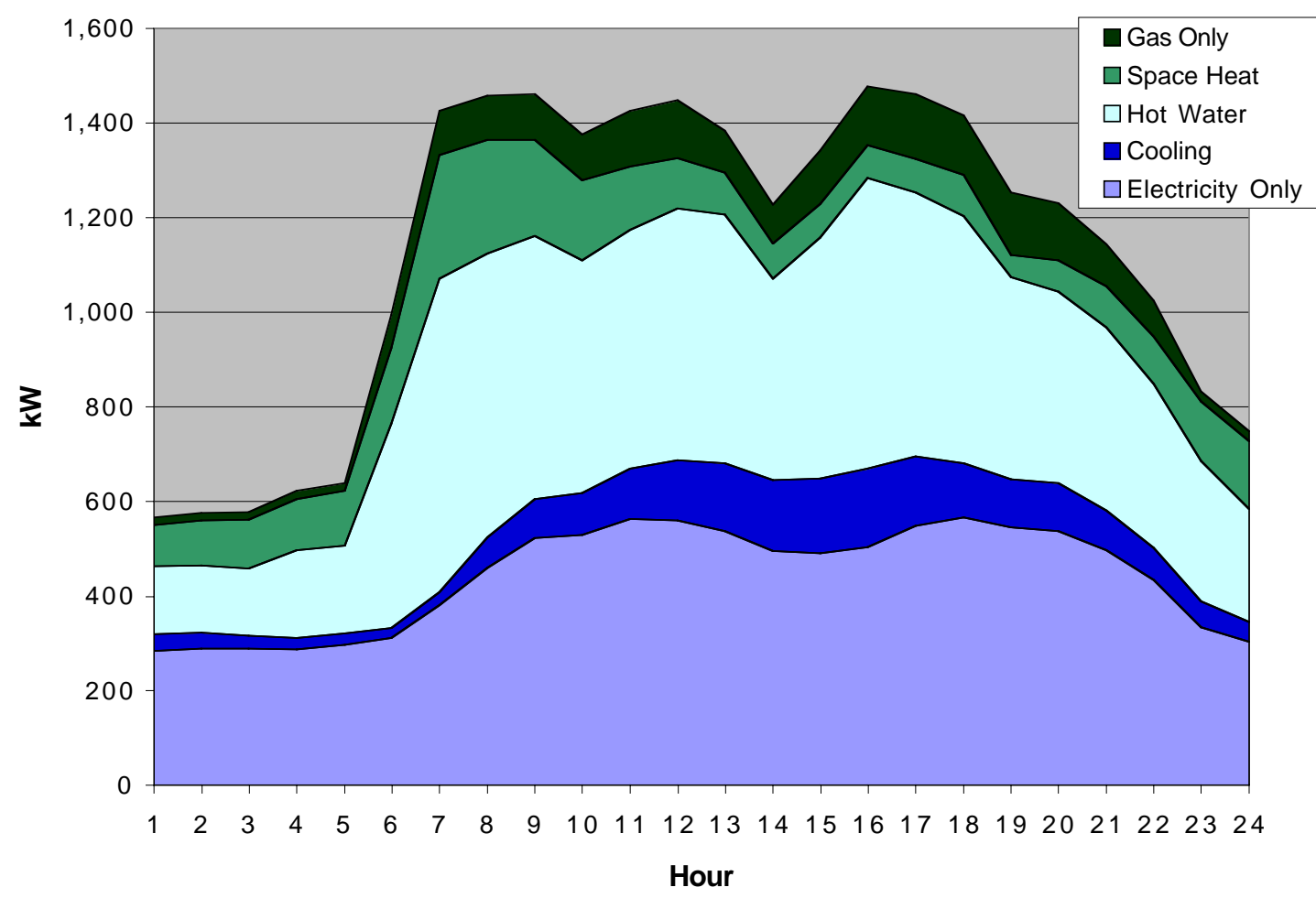

Figure 4. January weekday energy load inputs for the base-case small commercial/ residential $\mu$ Grid.

The load inputs for the base-case $\mu$ Grid are compared with the energy inputs for the laundromat, one of the two buildings that were analyzed independently (see

Figure 5 below). Figure 5 shows a low electricity load factor of 50 percent for the laundromat, and a comparatively high ratio of gas use to electricity use, including a large gas-only load for dryer heat. The peak electricity load for the laundromat never exceeds $17 \mathrm{~kW}$. 


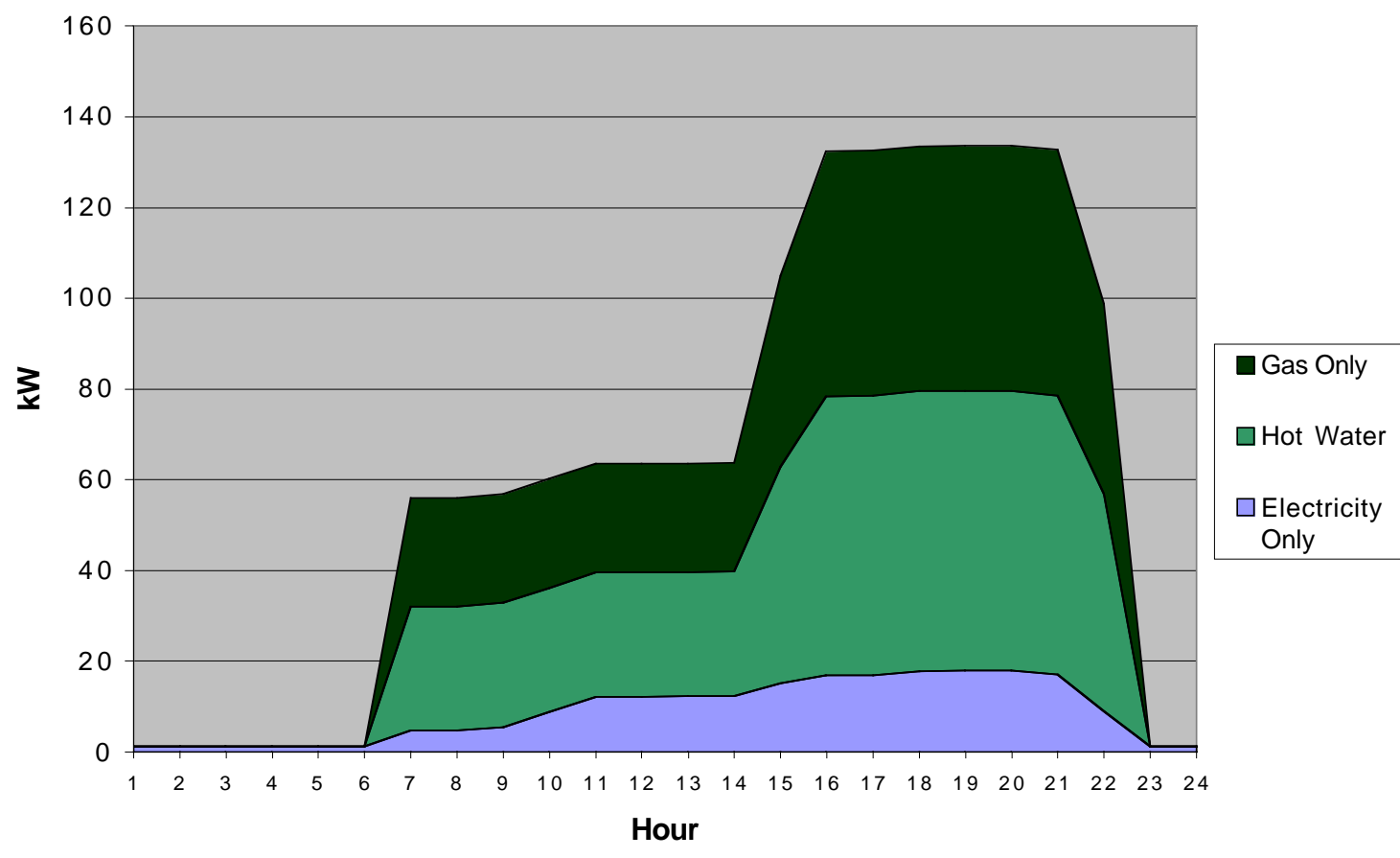

Figure 5. January weekday energy load inputs for the laundromat. Inputs are simplified, assuming no central HVAC. 
Table 1 below shows the results from the five DER-CAM runs of different building combinations within the small commercial/ residential $\mu$ Grid. Three cases represent variations on the base-case $\mu \mathrm{Grid}$, and two cases analyze individual buildings within the $\mu$ Grid.

Table 1. Results for the five cases of the small commercial/ residential $\mu \mathrm{Grid}$

\begin{tabular}{|c|c|c|c|c|c|}
\hline & $\begin{array}{c}\mu \text { Grid } \\
\text { (Base-Case) }\end{array}$ & $\begin{array}{c}\mu \text { Grid } \\
\text { (Double Size) }\end{array}$ & $\begin{array}{c}\mu \mathrm{Grid} \\
\text { (No Residences) }\end{array}$ & Hospital Only & $\begin{array}{c}\text { Laundromat } \\
\text { Only }\end{array}$ \\
\hline $\begin{array}{c}\text { Installed } \\
\text { Capacity }(\mathrm{kW})\end{array}$ & $775 \mathrm{~kW}$ & $1,555 \mathrm{~kW}$ & $775 \mathrm{~kW}$ & $330 \mathrm{~kW}$ & $25 \mathrm{~kW}$ \\
\hline $\begin{array}{l}\text { Peak Electric } \\
\text { (No Demand } \\
\text { Reduction) } \\
\end{array}$ & $\begin{array}{c}886 \mathrm{~kW} \\
\text { July weekday }\end{array}$ & $\begin{array}{c}1,772 \mathrm{~kW} \\
\text { July weekday }\end{array}$ & $\begin{array}{c}854 \mathrm{~kW} \\
\text { July weekday }\end{array}$ & $\begin{array}{c}406 \mathrm{~kW} \\
\text { Jan weekend }\end{array}$ & $17 \mathrm{~kW}$ \\
\hline $\begin{array}{c}\text { Peak Electric } \\
\text { (Cooling Demand } \\
\text { Reduction) }\end{array}$ & $\begin{array}{c}730 \mathrm{~kW} \\
\text { July weekday }\end{array}$ & $\begin{array}{c}1,463 \mathrm{~kW} \\
\text { July weekday }\end{array}$ & $\begin{array}{c}706 \mathrm{~kW} \\
\text { July weekday }\end{array}$ & $\begin{array}{c}395 \mathrm{~kW} \\
\text { Jan weekend }\end{array}$ & $\begin{array}{c}\text { No cooling } \\
\text { technologies }\end{array}$ \\
\hline $\begin{array}{l}\text { Percent of Peak } \\
\text { met by } \mathrm{DG}^{\mathrm{a}}\end{array}$ & All & All & All & $84 \%$ & All \\
\hline $\begin{array}{c}\text { Electricity Load } \\
\text { Factor }\end{array}$ & $75 \%$ & $75 \%$ & $75 \%$ & $79 \%$ & $50 \%$ \\
\hline $\begin{array}{c}\text { Installed } \\
\text { Technologies } \\
\text { (Number of } \\
\text { Generators) }\end{array}$ & $\begin{array}{l}\text { CHPGA-K- } \\
55(5) \\
\text { COOLGA-K- } \\
500(1)\end{array}$ & $\begin{array}{c}\text { CHPGA-K-500 } \\
(1) \\
\text { CHPGA-K-55 (1) } \\
\text { COOLGA-K-500 } \\
\text { (2) }\end{array}$ & $\begin{array}{c}\text { CHPGA-K-55 } \\
\text { (5) } \\
\text { COOLGA-K- } \\
500(1)\end{array}$ & $\begin{array}{c}\text { CHPGA-K- } \\
55 \text { (4) } \\
\text { COOLGA-K- } \\
55(2)\end{array}$ & $\begin{array}{c}\text { CHPGA-K- } \\
25 \text { (1) }\end{array}$ \\
\hline $\begin{array}{l}\text { Average } \mathrm{COE}^{\mathrm{d}} \\
(\$ / \mathrm{kWh})\end{array}$ & 0.068 & 0.069 & 0.080 & 0.049 & 0.075 \\
\hline $\begin{array}{c}\text { Percent of Total } \\
\text { Gas Load met } \\
\text { by CHP }\end{array}$ & $81 \%$ & $81 \%$ & $81 \%^{\mathrm{f}}$ & $84 \%$ & $36 \%$ \\
\hline $\begin{array}{c}\text { Percent of } \\
\text { Potential CHP } \\
\text { Load met by } \\
\text { CHP }^{\mathrm{g}}\end{array}$ & $95 \%$ & $95 \%$ & $95 \%$ & $94 \%$ & $67 \%$ \\
\hline $\begin{array}{c}\text { Cogeneration } \\
\text { Savings }(\$ / G J)^{h}\end{array}$ & 7.04 & 7.01 & 7.04 & 7.35 & 3.09 \\
\hline
\end{tabular}

a After cooling demand reduction

${ }^{\mathrm{b}}$ Calculated for January weekday, prior to cooling demand reduction

${ }^{c}$ See Appendix D for the database of DER-CAM technologies. A CHP prefix means the generator waste heat can be used for heat loads; a COOL prefix means the waste heat can be used for absorption cooling.

${ }^{d}$ The average cost of electricity is the total annual electricity bill divided by the total annual electricity load. Total bill includes fuel costs, levelized investment costs, variable and fixed O\&M, and electricity purchased from the utility.

${ }^{\mathrm{e}}$ This is the percent of gas-only, hot-water, and space-heat loads met by CHP on an annual basis

${ }^{\mathrm{f}}$ Assumed that residences do not have retrofits for CHP; therefore, electricity demand and not heat demand account for any difference with the basic $\mu$ Grid.

${ }^{g}$ This is the percent of hot-water and space-heat loads met by CHP on an annual basis.

${ }^{\text {h }}$ Savings calculated based on a natural gas price of $\$ 8.66 / \mathrm{GJ}$.

Cogeneration Savings $=($ Total annual heat load met by CHP/Total annual heat load $) * \$ 8.66 / \mathrm{GJ}=\$ / \mathrm{GJ}$ saved 
The following figures show the distributed technologies adopted in the base-case and the loads that are met by each technology. The generators that are commonly installed are the 55- and $500-\mathrm{kW}$ natural gas reciprocating generators (GA-K-55 or 500), ${ }^{11}$ retrofitted with cooling or CHP technologies.

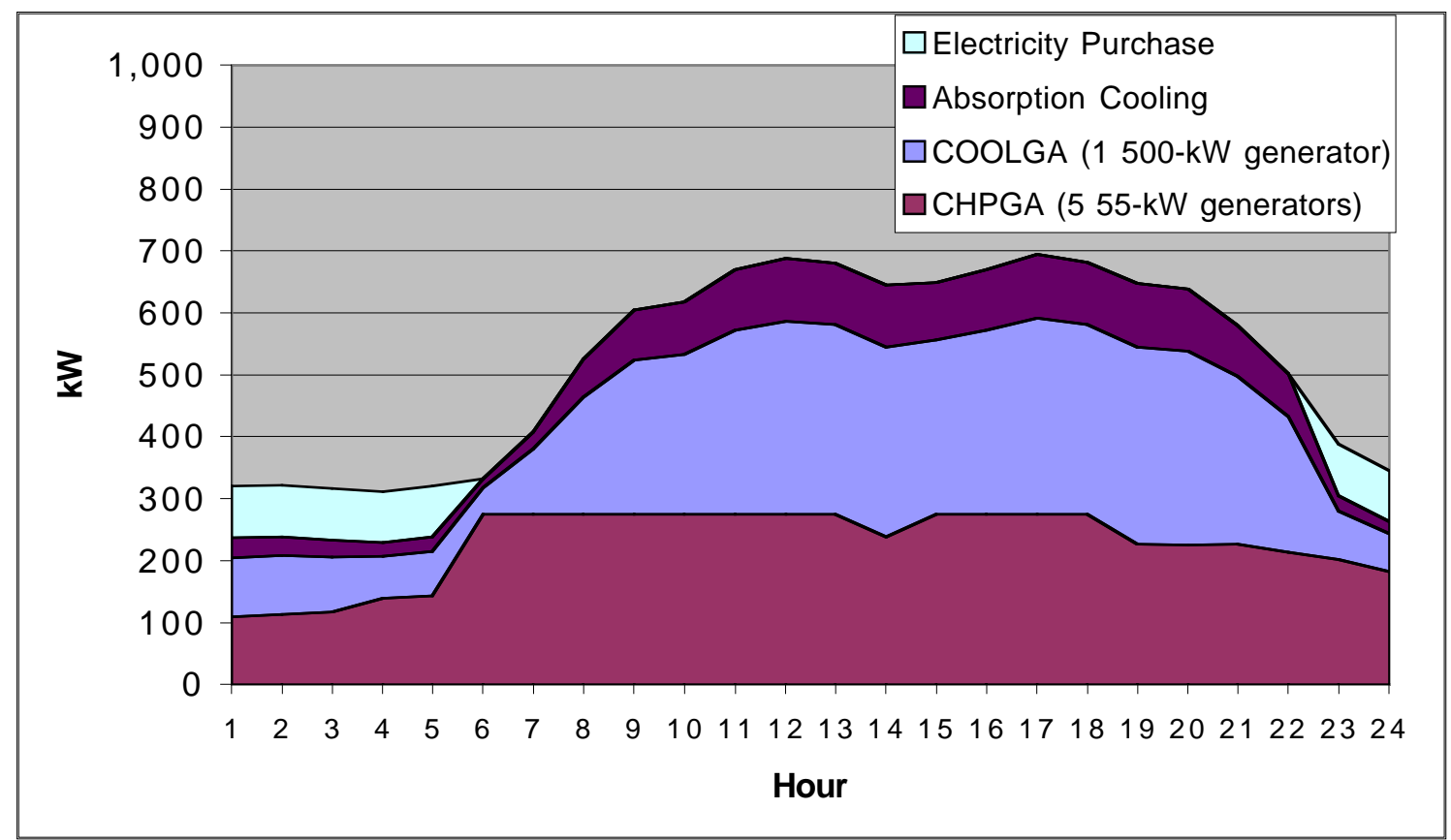

Figure 6. How January weekday electricity loads are met in the base-case $\mu \mathrm{Grid}$.

The absorption cooling band represents a demand reduction as electricity cooling loads are displaced by absorption chillers. Though not shown in any of the examples here, this absorption cooling demand reduction also has the potential to transfer the peak electricity days from summer to winter, because summer electricity peaks are attributable primarily to cooling loads while other electric loads, such as lighting, are lower. Figure 6 shows that, on this day, 95 percent of the electricity loads are met with on-site generation or demand reduction, although the $\mu$ Grid continues to purchase electricity from SDG\&E during the cheapest times of the day (i.e., hours between 22:00 and 5:00 when TOU tariff rates are lowest).

\footnotetext{
${ }^{11}$ For a complete listing of all technologies in the DER-CAM database, see Appendix D
} 


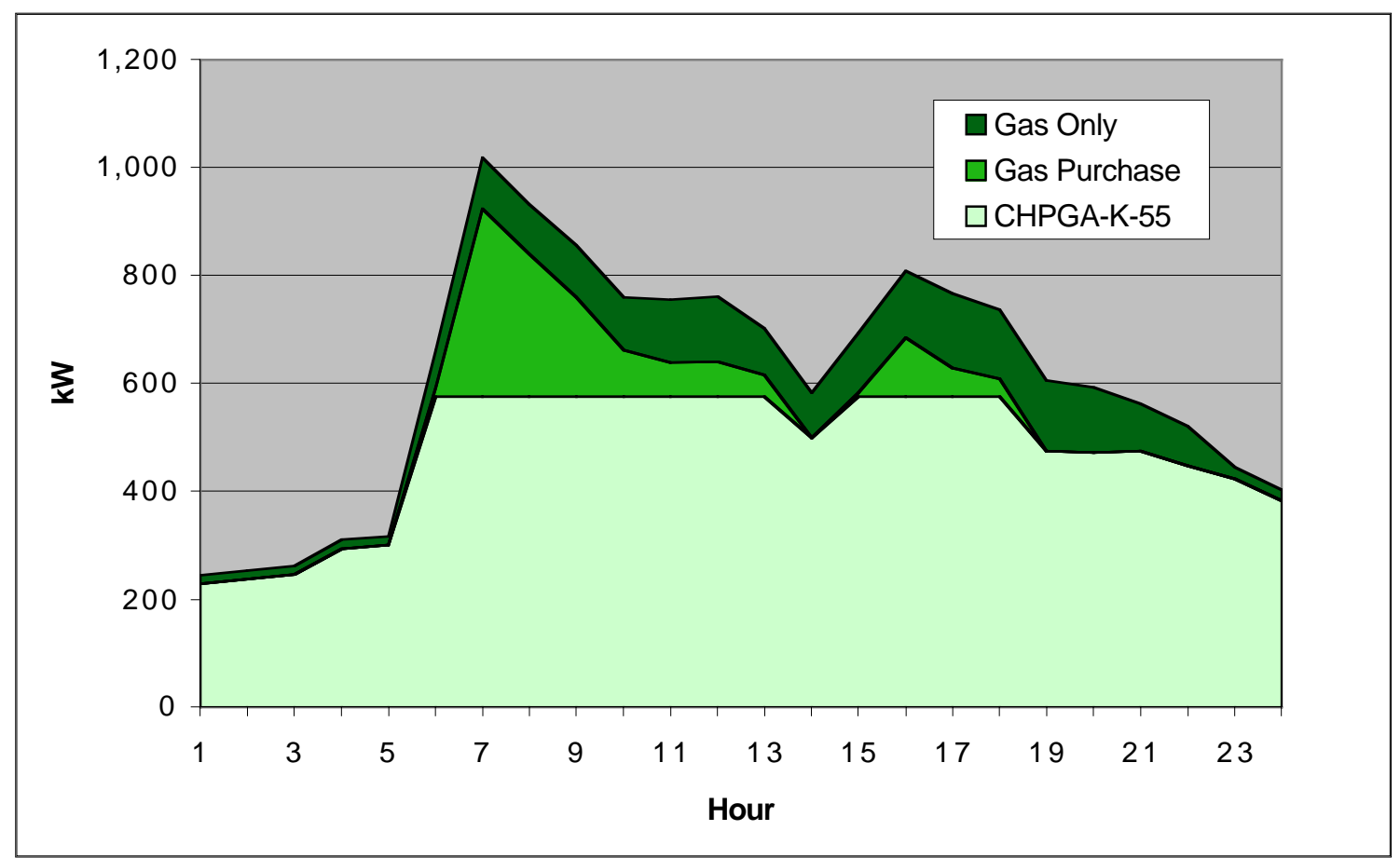

Figure 7. How January weekday natural gas loads are met in the base-case $\mu \mathrm{Grid}$. The CHP output shown in the lowest band is supplied by five $55-\mathrm{kW}$ generators.

Figure 7 shows how natural gas loads are met in the base-case $\mu$ Grid. On an annual basis, CHP accounts for 81 percent of all gas loads and 95 percent of the hot-water and space-heat loads that can potentially be met by CHP. The $\mu$ Grid is required to purchase additional gas, especially in the early morning hours when hot-water and space-heat loads are large but electricity demand has not reached its peak. 
Figure 8 below shows capacity installations for the five example cases. All cases other than the hospital install on-site generation that can meet their highest electrical peak during the year although no example $\mu$ Grid disconnects completely from the utility grid.

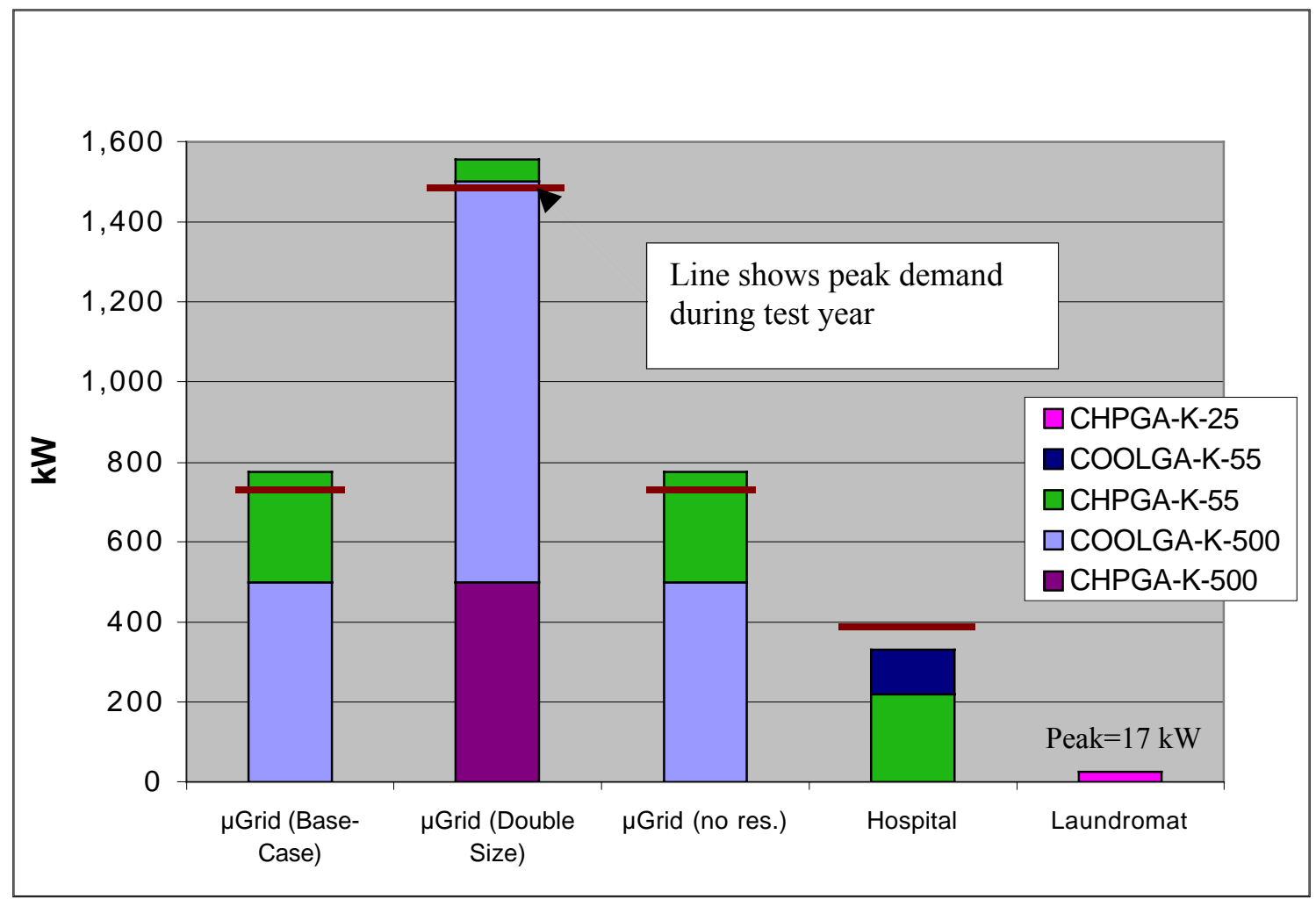

Figure 8. Installed capacity for the five $\mu \mathrm{Grid}$ cases in the small commercial/ residential neighborhood. More than one piece of equipment may be included in a single band (e.g. the light blue column for the double-size $\mu \mathrm{Grid}$ represents two $500-\mathrm{kW}$ generators.)

A comparison of the economics of the five cases can be made by looking at the average cost of electricity (COE) and the cogeneration savings for each customer. The average COE is the total annual electricity bill divided by total annual electricity use where the electricity bill is a function of generator fuel costs, levelized investment and fixed costs, variable O\&M, and electricity purchases. The average natural gas cost is equivalently the total gas bill divided by the total gas load where the gas bill is determined by the cost of gas purchases for all uses other than generator fuel (i.e. the gas bill includes purchases for gas-only loads and heat loads not met by CHP). This value assumes a baseline natural gas cost of $\$ 8.66 / \mathrm{GJ}$. The average natural gas cost reflects the savings achieved as CHP displaces gas purchases; the potential savings are lower for customer's with large gas-only loads. 


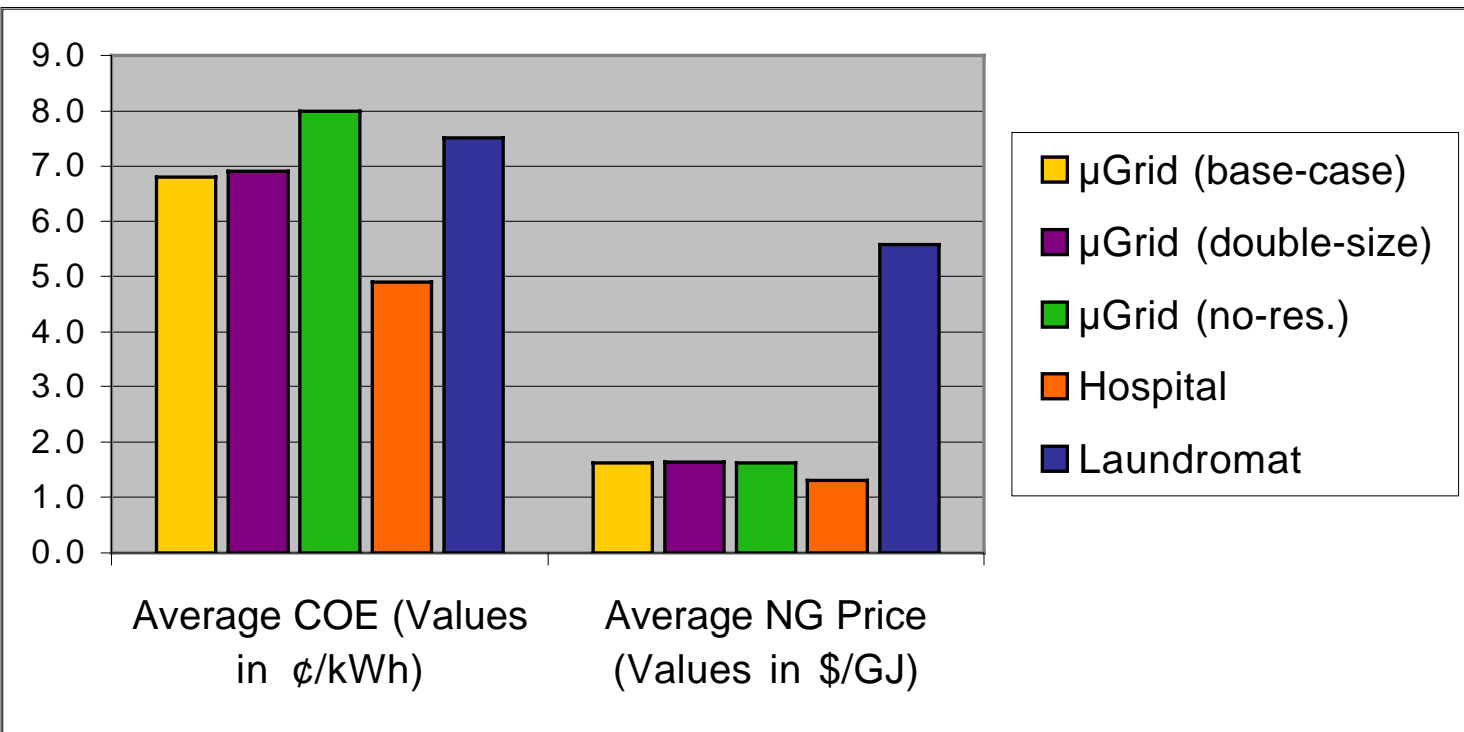

Figure 9. Average cost of electricity and natural gas for the five cases. The average natural gas cost does not include fuel purchases. The baseline natural gas cost is assumed to be \$8.66/GJ.

The average COE for the base-case $\mu$ Grid and double-size $\mu$ Grid are 6.8 and $6.9 \notin / \mathrm{kWh}$, respectively. These costs show that, for the double-size $\mu$ Grid analyzed here, economies of scale do not make a significant difference in the overall $\mathrm{COE}$, although the technologies adopted are different for the double-size $\mu$ Grid than for the base-case $\mu$ Grid $(500-\mathrm{kW}$ rather than $55-\mathrm{kW}$ generators). The highest $\mathrm{COE}$ case is the no-residence $\mu$ Grid where the technology investment is the same as for the base-case $\mu$ Grid (see Figure 8) but there are fewer kWh over which to spread the levelized generator costs. This demonstrates the benefits of complementary electricity loads, because residential electricity use is highest in the early evening, and the peak use of commercial and office customers is in the afternoon. Results show that the average COE is lowest for the hospital at $4.9 \phi / \mathrm{kWh}$, which does not provide a strong incentive for the hospital to connect to the larger $\mu$ Grid. The laundromat, however, saves an average of 0.7 $\varnothing / \mathrm{kWh}$ by purchasing electricity through the $\mu$ Grid (base-case).

There is no significant variation in gas costs among the three $\mu$ Grid cases $(\$ 1.62-\$ 1.65$ per GJ). The cogeneration savings are again highest for the hospital, which is able to displace 84 percent of its gas load with CHP (see Table 1). The laundromat makes a poor case for installing on-site generation independently from the rest of the $\mu \mathrm{Grid}$. Though the laundromat has high heat loads and could benefit substantially from the use of CHP, it has the highest relative gas-only load and therefore displaces only 36 percent of its total gas load with CHP. In addition, the low electrical load of the laundromat precludes the benefits of CHP since generator electricity production is never high enough to produce adequate waste heat. This result demonstrates another benefit of complimentary energy loads, since the laundromat realizes greater economic benefits by sharing electricity and waste heat from larger generators with other customers in a $\mu$ Grid. These two individual customer cases demonstrate the large variability in the economics of DER adoption, which depends on the size of the customer and the ratio and overlap of electricity and heat loads as a determinant of potential CHP benefits. 


\subsection{GIS Results}

Figure 10 is a map of the small commercial/residential neighborhood showing individual buildings as they were classified for energy end-use purposes. The land parcels show property boundaries, which may include parking spaces, walkways, or other outdoor areas such as lawns and gardens.
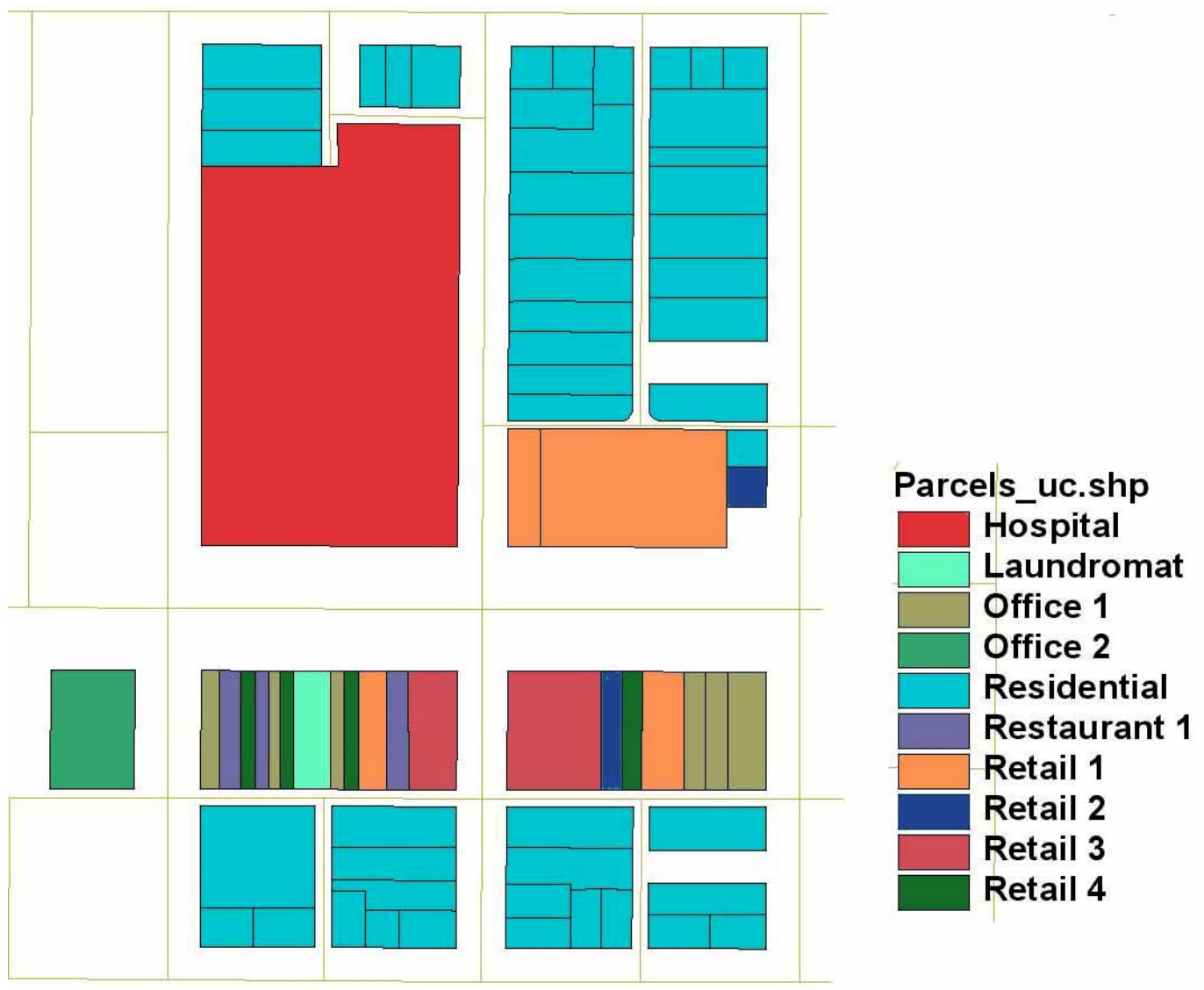

Figure 10. GIS map of individual buildings, classified according to their energy needs. For more detail on each of the building classifications, see Appendix B on load-shape preparation.

First, a GIS was used to identify the buildings large enough to accommodate a generator. The largest generator chosen by the DER-CAM model for this neighborhood is a $500-\mathrm{kW}$ naturalgas reciprocating engine. According to manufacturer specifications, the footprint of this generator is $34 \mathrm{~m}^{2}$. To judge the available siting space, it is assumed that the generator cannot occupy more than 1 percent of the building floor area. Furthermore, it is assumed that the generator would not be sited at a residence. These constraints left five possibilities for generator location: the hospital, three retail sites, and a large medical office building. These sites are shown in Figure 11 highlighted in yellow. 


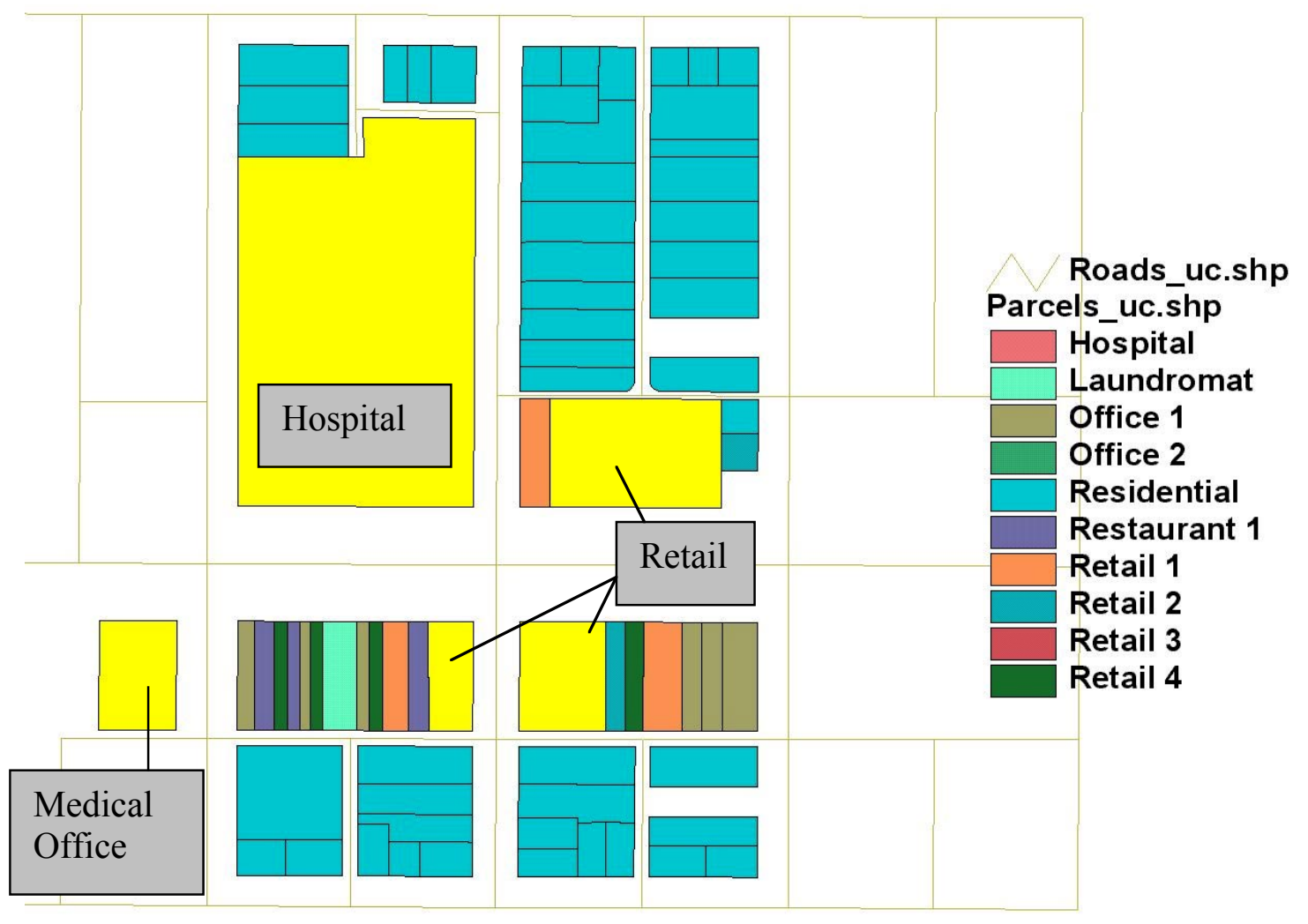

Figure 11. Possible locations for the 500-kW natural gas generator: the hospital, a large medical office building, and three retail sites.

Next, an approximation of the feasibility of heat transfer from the five possible generator sites was made. The distance was measured between each site and the rear of the hospital, which is the largest heat sink in the $\mu$ Grid and the most distant building requiring CHP. Heat-transfer loss is a considerable constraint when constructing energy-supply networks on the scale described here. Reasonable transfer distances for this type of CHP are assumed to be on the order of 100 to $200 \mathrm{~m}$. 


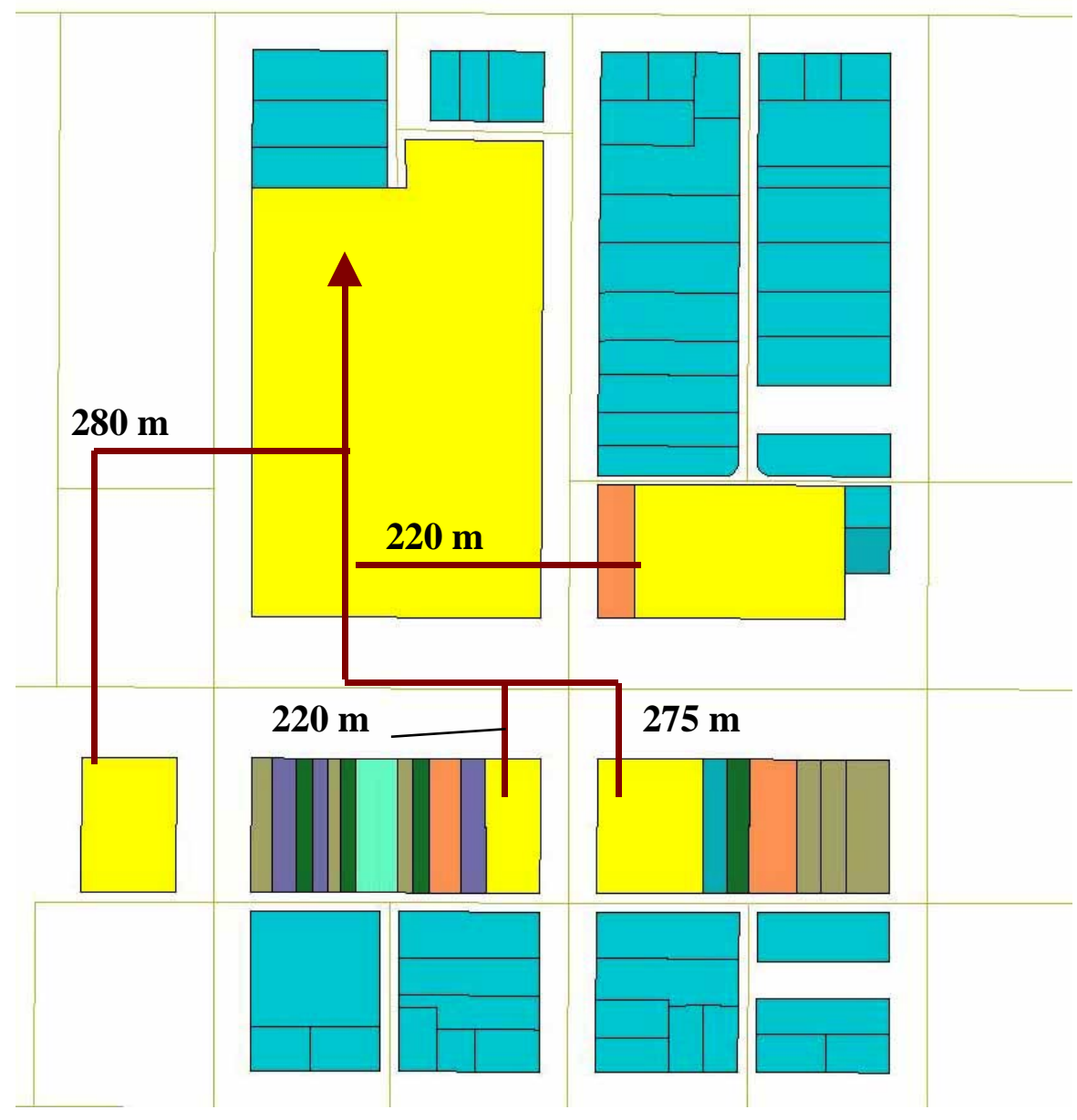

Figure 12. Measured distances between potential generator sites and the hospital..

As shown in Figure 12, the required heat-transfer distances for this particular example are relatively large, and the heat loss may be significant without considerable retrofits and insulation. This suggests that heat-transfer losses should be addressed directly in further studies of the economic feasibility of on-site distributed generation, optimizing the economic tradeoffs between heat-transfer loss and insulation upgrades. The economics of heat transfer can be quantified and included as an optimization parameter in DER-CAM.

In the third step of this analysis a GIS was used to address local noise restrictions. This particular neighborhood has commercial zones located adjacent to residential zones; the latter have more restrictive noise regulations. (A description of San Diego noise ordinances is included in Appendix F.) DER-CAM results show that on-site generation would operate throughout the entire day and must therefore conform to the most restrictive noise level of 50 decibels between the hours of 22:00 and 7:00. ${ }^{12}$ Manufacturer specifications give the noise levels of the three generators selected by DER-CAM (25-, 55-, and 500-kW natural gas engines) as 76,79 , and $93 \mathrm{~dB}$ at $7 \mathrm{~m}$, respectively. The corresponding $\mathrm{dB}$ levels at different distances can then be calculated by making the simplifying assumptions that insulation will quiet the

\footnotetext{
${ }^{12}$ San Diego noise ordinances indicate that a noise source located on the border of two zoning districts must conform to the arithmetic mean of the standards for the two districts. Here, that value is $50 \mathrm{~dB}$.
} 
generators by approximately $25 \mathrm{~dB}$ and that generator noise emanates from a point source. ${ }^{13}$ Distances of 20,40 , and $60 \mathrm{~m}$ are chosen as representative examples, and the $\mathrm{dB}$ value at each of these points is calculated. The minimum distance at which the $500-\mathrm{kW}$ generator noise will be reduced to the maximum allowable level is $60 \mathrm{~m}$. The magnitude of noise interference with local residences is determined by adding equidistant buffer zones to potential DG sites and approximating the noise level in each region. Figure 14 shows these noise buffers around the hospital and a retail store and the potential overlap with local residences.

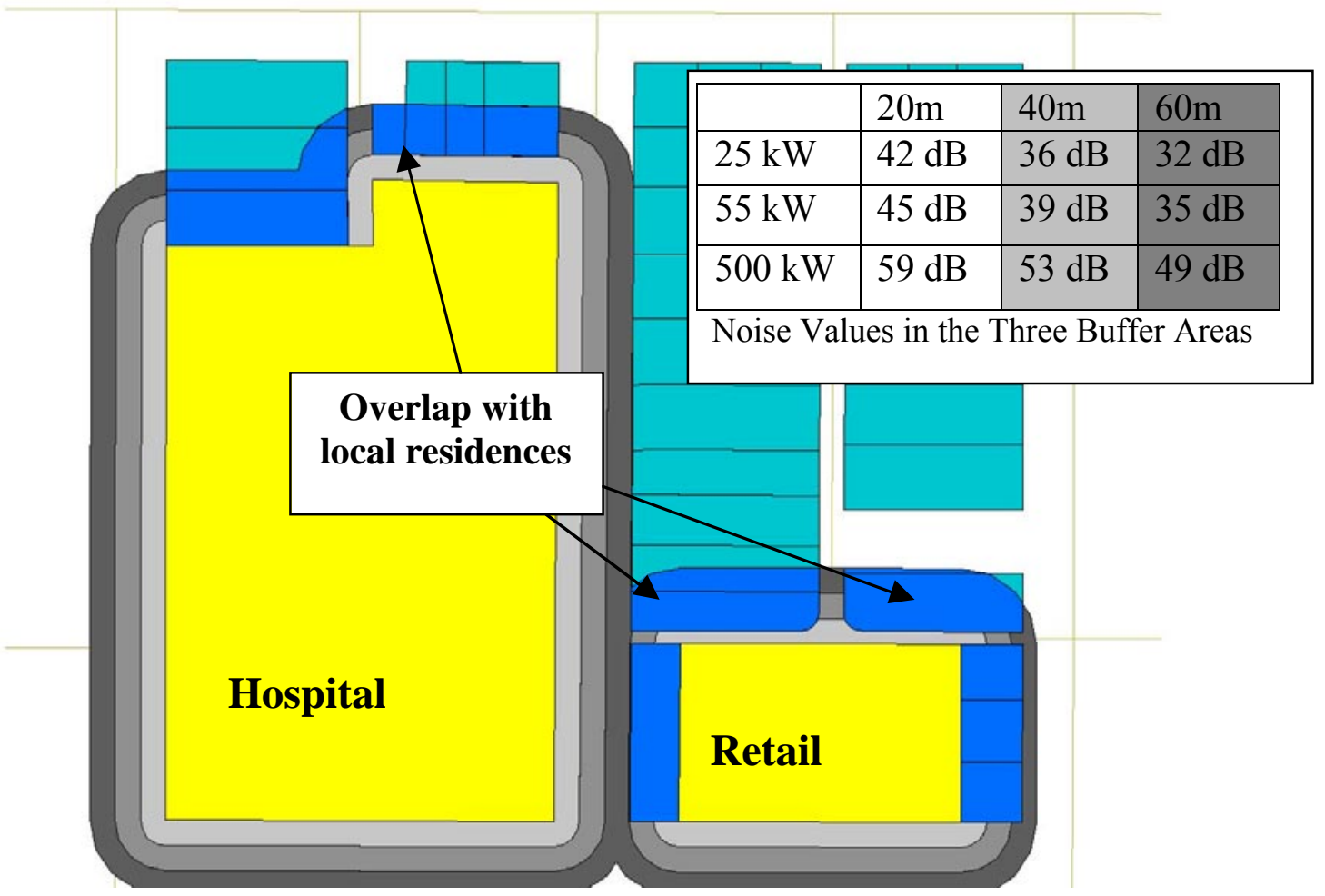

Figure 13. Buffer zones at 20, 40, and $60 \mathrm{~m}$ showing noise dissipation over distance and possible interference with local residences.

Figure 13 shows that there will be some noise interference with residences in the area immediately surrounding the generator sites. Within a radius of $60 \mathrm{~m}$ from the retail store, at which point the $500-\mathrm{kW}$ generator noise output would be reduced to $50 \mathrm{~dB}$, three residential buildings and four commercial sites would be affected by a noise level higher than zoning regulations allow. The decibel values used in this example do not account for sound reflection off of buildings or additional sound-proofing retrofits that would almost certainly be used in a scenario like this one. However, the GIS analysis method exemplified here can be applied to any problem involving the dissipation of noise or emissions over distance, no matter what absolute values are used.

\footnotetext{
${ }^{13}$ See the above section on completed tasks for a more detailed description of this calculation. For a reference on achievable levels of generator soundproofing see http://www.soundstop.com/soundstop.htm.
} 


\section{Summary and Future Work}

\subsection{Summary of Research}

The research presented here shows how the DER-CAM economic optimization model of distributed generation adoption can be used in conjunction with a GIS analysis of local land-use constraints affecting the deployment of DER. Based on the premise that certain customers have complementary energy loads and would mutually benefit from shared on-site generation, a hypothetical $\mu$ Grid was identified in the San Diego area and energy end-use loads were applied to the selected customers in the $\mu$ Grid. Using these energy loads as inputs, the DER-CAM model identified various combinations of natural gas reciprocating engines as the lowest-cost options for the five $\mu$ Grid cases analyzed. A GIS was then used to address three issues affecting the feasibility of deploying these generators at the San Diego site: the amount of available open space to house the generator, the possible energy losses from transporting generator waste heat among customers, and violation of zoning laws restricting noise. The methods described here exemplify the simple, straightforward manner in which a GIS can be used to identify, quantify, and convey spatial issues related to DER deployment.

The hospital proved to be a special case within the $\mu$ Grid analyzed in this study. With large heat sinks and a relatively flat load, the hospital is a good candidate for installing on-site generation independent from the rest of the $\mu$ Grid. However, the hospital is especially sensitive to local land-use restrictions. Generation technologies must be close enough to the hospital to minimize heat-transfer losses but also out of earshot of generator noise. A GIS map shows that the distance required for generator noise to dissipate to an allowable level, on the order of $60 \mathrm{~m}$, is smaller than the 100 to $200 \mathrm{~m}$ distance at which heat-transfer loss becomes a problem. It might, therefore, be possible to avoid noise interference without serious heat-transfer losses. This may be enough of an incentive for the hospital to join the larger $\mu$ Grid and use generators located away from its immediate surroundings.

\subsection{Limitations of Data and Analysis Method}

The primary purpose of this project is to demonstrate the ability of a GIS to model local landuse constraints to the siting of on-site distributed generation. The GIS portion of this project was conducted in conjunction with an economic analysis of DG adoption using DER-CAM. Thus, it was necessary to look at $\mu$ Grid planning on an individual building scale because individual building energy loads must be quantified in order to address the energy and economic demands of a $\mu \mathrm{Grid}$. However, in narrowing the geographic area for analysis to a small neighborhood scale, the ability of GIS to accurately analyze land-use constraints was limited. This is primarily because of the limitations on publicly available GIS data, which are collected and shared mainly for the purpose of conducting geographic analyses on a city-wide or larger scale. The GIS data provided by SANDAG were collected mainly to reflect variation among neighborhoods, not within them. Individual building data from SanGIS identify property boundaries by building owner but do not distinguish individual tenants within commercial sites or details such as parking lots or open spaces within a single property. This level of detail is required to study the land-use constraints addressed in this project. Therefore, several assumptions were made about the buildings in the $\mu$ Grid to fill in these gaps. This analysis is not 
intended as a literal suggestion, but as a template to show the potential contribution of a GIS to solve distributed generation siting issues. The real asset of a GIS is its ability to conduct city-, county-, or state-wide assessments of potential DG sites.

\subsection{Future Work}

It was beyond the scope of this project to analyze in detail the economics of all three example $\mu$ Grid neighborhoods. Because much of the initial GIS analysis of these neighborhoods has been completed, however, it is a logical next step to further compare the distributed generation adoption potential of the industrial area and the downtown office/retail area. Also, a closer look at building turnover patterns within the neighborhoods would help quantify the economic and land-use impacts of changing end users. It is quite possible that buildings will change within the $\mu$ Grid over the 15- to 20-year lifetime of the adopted DG technologies, so sensitivity to this type of variation is an important determinant of the economic feasibility of DG investment.

Several land-use constraints with wide impacts on distributed generation potential were not addressed in this study. These include customer access to high-pressure gas lines, existing constraints within the electricity infrastructure, and geographical or meteorological influences on renewable energy systems. These constraints were not analyzed partly because of the sensitivity of the applicable data, but they are nonetheless important factors that should be considered in future work if data become available.

An assessment of $\mu$ Grid development potential must account for different local constraints depending on whether existing buildings are retrofitted or a $\mu \mathrm{Grid}$ is incorporated into the planning of new development. This is certainly true not only from an electrical engineering standpoint but also for land-use constraints and the energy profiles of local end users. Neighboring buildings within developed cities have different land-use patterns than new development sites, where buildings tend to be larger and grouped together by similar building types, such as tracts of residential homes, strip malls, or large office complexes. For this reason, it would be worthwhile to consider $\mu$ Grid potential in areas of current development using the tools described here.

As mentioned above, the GIS portion of this analysis depends on detailed building-specific data for individual neighborhoods. GIS also has great potential to address local constraints on a larger scale. Making a large-scale geographic comparison of influences such as areas of new development, access to high-pressure gas, climate variation, distribution constraints, and areas of high electricity cost, one can first identify promising regions for DG adoption and then address the economics of each specific region.

The broad goal of this effort is to develop a tool that can forecast the likely deployment of DER in $\mu$ Grids. This GIS-driven approach is a counterweight to DER analyses that rely on macro characteristics of the economy and the installed base of host sites. Through detailed analysis of sample areas we hope to develop a more general method, where GIS is applied on a larger scale using automated processing of GIS data for identification of potential $\mu$ Grids. 


\section{References}

Akbari, H., L. Rainer, K. Heinemeier, J. Huang, and E. Franconi. 1993. "Measured Commercial Load Shapes and Energy-Use Intensities and Validation of the LBL End-Use Disaggregation Algorithm.” Berkeley CA: Lawrence Berkeley National Laboratory, pp. 224

Marnay, C., R. Blanco, K. Hamachi, C. Kawaan, J. Osborn and F. Rubio. 2000. "Integrated Assessment of Dispersed Energy Resources Deployment." Berkeley CA: Lawrence Berkeley National Laboratory Report LBNL-46082. June.

Marnay, C., J. Chard, K. Hamachi, T. Lipman, M. Moezzi, B. Ouaglal, and A. Siddiqui. 2001. "Modeling of Customer Adoption of Distributed Energy Resources." Berkeley CA: Lawrence Berkeley National Laboratory Report LBNL-49582. August.

Marnay, C., R. Richey, S. Mahler, S. Bretz, and R. Markel. 1997. "Estimating the Environmental and Economic Effects of Widespread Residential PV Adoption Using GIS and NEMS.” Berkeley CA: Lawrence Berkeley National Laboratory Report LBNL41030. October.

Rubio, F., A. Siddiqui, C. Marnay and K. Hamachi. 2001. "CERTS Customer Adoption Model." Berkeley CA: Lawrence Berkeley National Laboratory Report LBNL-47772. March.

Sezgen, O., C. Marnay, and S. Bretz. 1998. "Wind Generation in the Future Competitive California Power Market.” Berkeley CA: Lawrence Berkeley National Laboratory Report LBNL-41134. March.

SCE, S. C. E. 1989. "End Use Metered Data for Commercial Buildings.” ADM for SCE, pp. 222.

Siddiqui, A., C. Marnay, K. Hamachi and F. Rubio. 2001. "Customer Adoption of Small-Scale On-Site Power Generation.” Berkeley CA: Lawrence Berkeley National Laboratory Report LBNL-47896. April.

The above reports are available at http://eetd.lbl.gov/ea/EMS/EMS_pubs.html 


\section{Appendix A: San Diego $\mu$ Grid Example Cases}

Below are brief descriptions of the three San Diego $\mu$ Grid example sites analyzed in this study and the customer types included in each. The small commercial/residential site was analyzed in more detail than the other two sites for this report.

\section{A.1 Downtown Office/Retail}

This area is dominated by a large office building and retail shopping center and is characterized by a lack of late-night loads. Customer types in the office/retail area include:

- $\quad$ a large office building containing a mixture of businesses;

- $\quad$ a large retail shopping center;

- a hotel encompassing two sites with a total of approximately 500 rooms;

- a movie theater;

- $\quad$ several fast food restaurants characterized by lunchtime peaks;

- a supermarket;

- $\quad$ a bus depot/transit center.
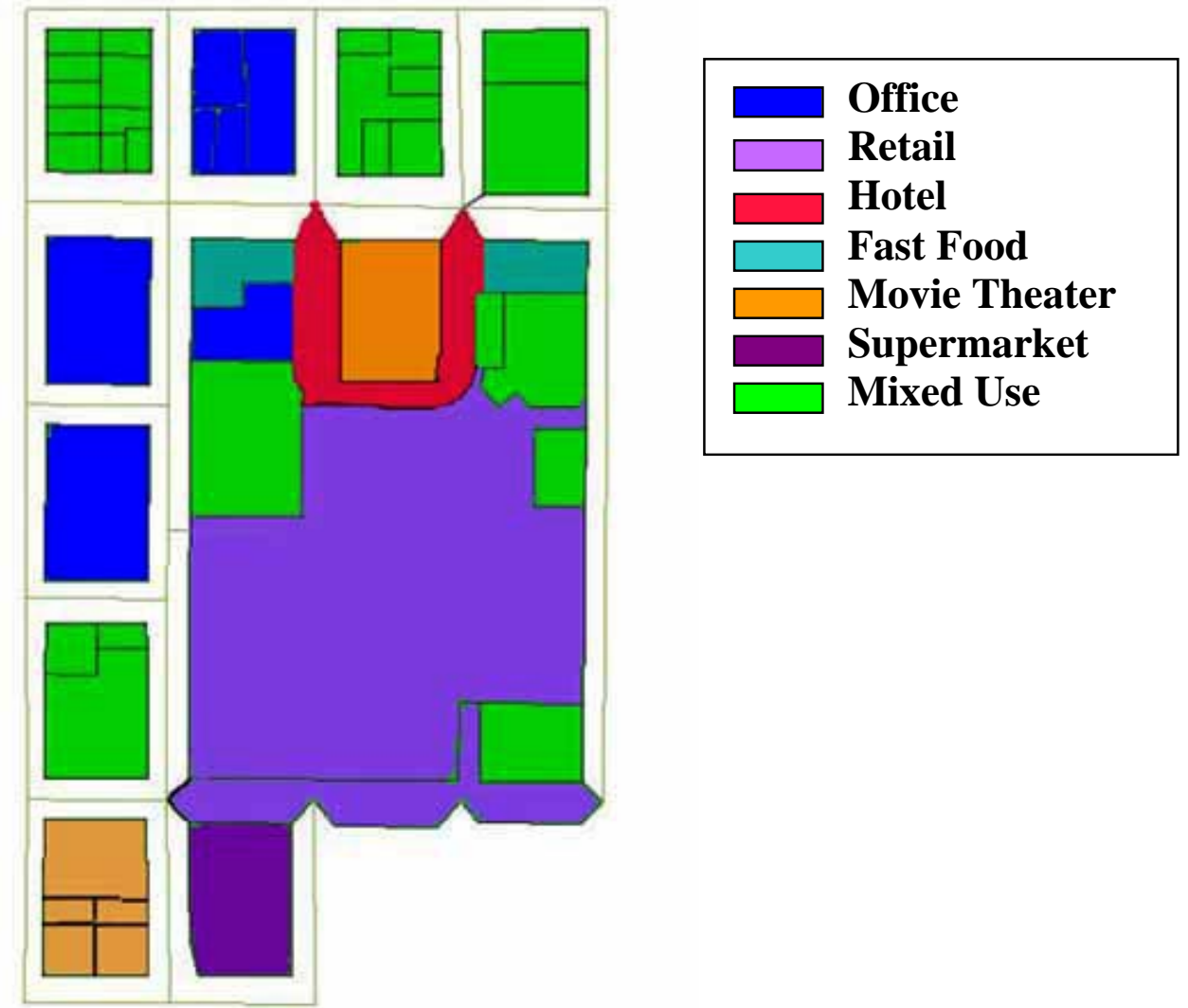

Figure A-1. Map of buildings in the downtown office/retail area. 


\section{A.2 Small Commercial/Residential}

Customer types in the commercial/residential area include:

- $\quad$ office buildings with typical business hours and loads, including an insurance agent and a property management company;

- $\quad$ a medical office building with typical business hours but higher-than-normal loads because of medical equipment;

- $\quad$ approximately 45 small residences in the surrounding blocks;

- $\quad$ retail stores with typical business hours (10:00-18:00) and non-energy-intensive retail services, e.g., a clothing retail store;

- retail stores with higher-than-normal electricity loads for services such as copying and printing;

- $\quad$ retail businesses that are open late hours, such as a video store;

- $\quad$ retail stores with higher-than-normal heat loads, including a hair salon and a spa;

- $\quad$ restaurants serving lunch and dinner;

- a small hospital with emergency services;

- a laundromat containing 50 clothes washers and 40 dryers.

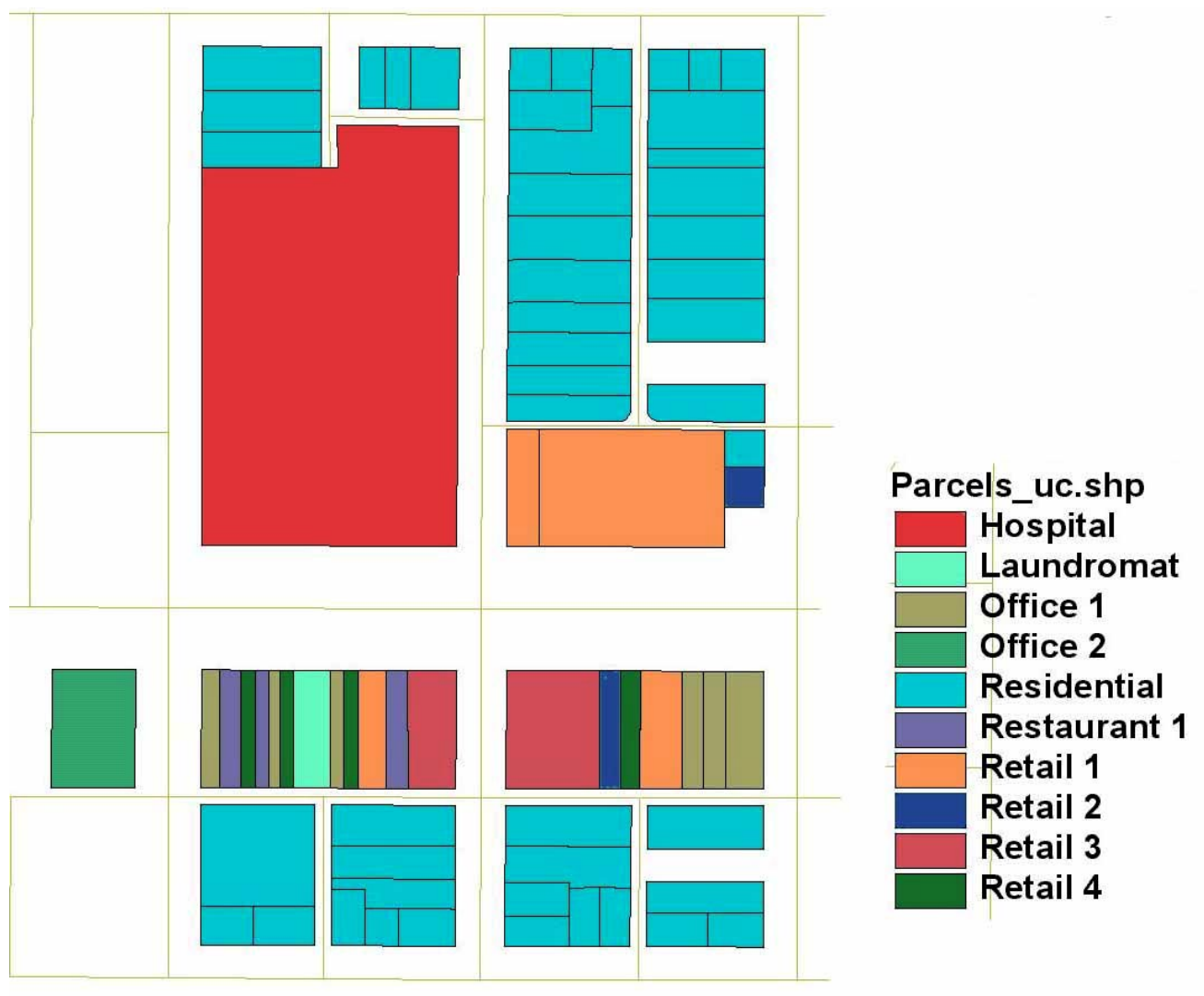

Figure A-2. Map of buildings in the small commercial/residential area. 


\section{A.3 Industrial}

This area contains open lots and warehouse spaces good for DG siting. It also has a higher preexisting noise level than the other two areas studied Customers in the industrial area include:

- $\quad$ auto dealerships and auto lots;

- $\quad$ repair shops including auto and boat repair;

- a warehouse;

- $\quad$ several small offices;

- a water bottling plant;

- $\quad$ some restaurants;

- a telephone exchange station characterized as a sensitive load.
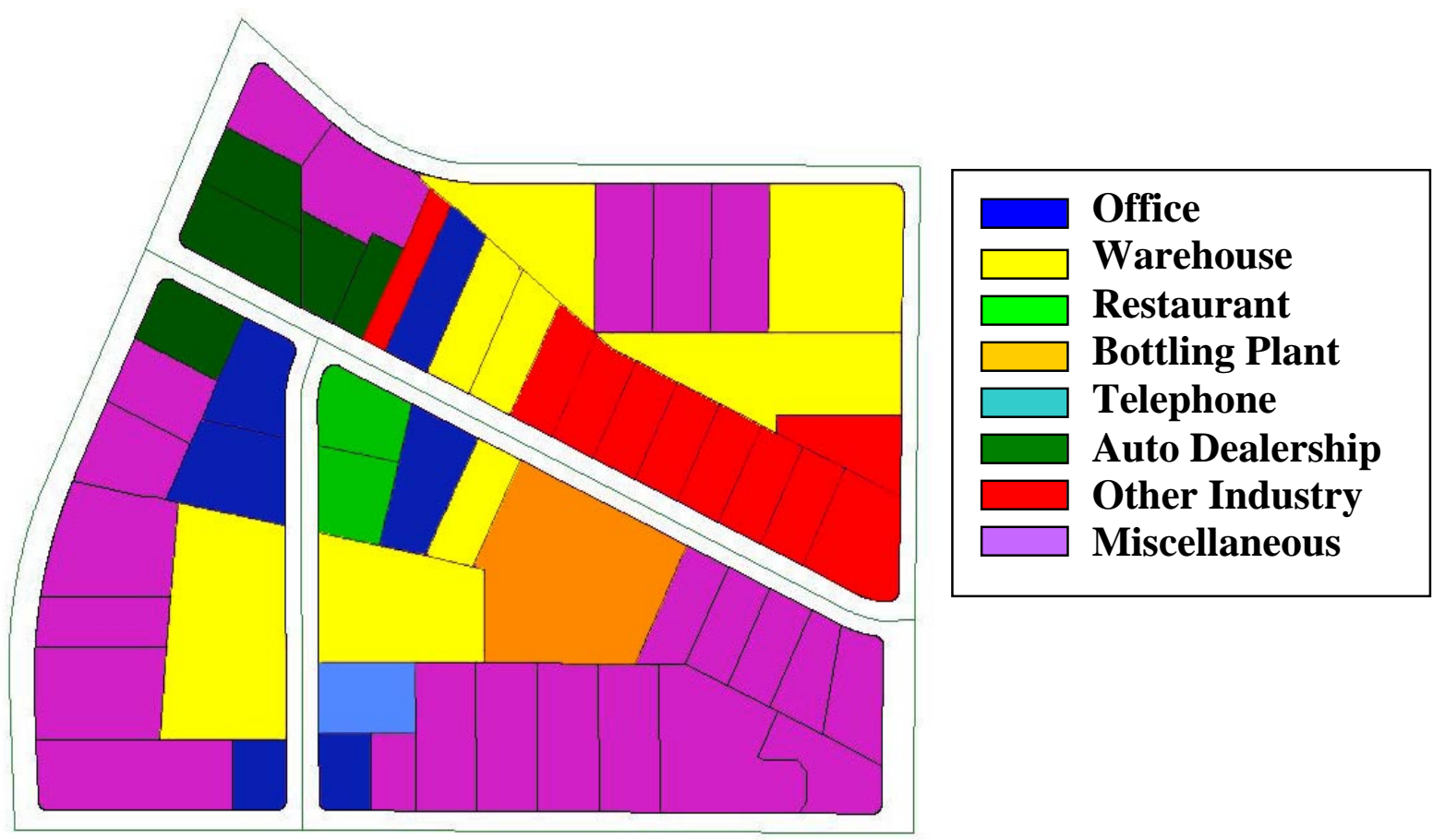

Figure A-3. Map of buildings in the industrial area. 


\section{Appendix B： Preparation and Selection of Energy Load Shapes}

This analysis uses a combination of metered and simulated end-use load shape data. A set of actual customer load profiles is vital for producing credible results representing the costminimizing deployment of DER technology. End-use metered loads for commercial buildings are not widely available, however. Berkeley Lab had an available archived set of commercial hourly load data, collected by Southern California Edison (SCE) in 1988-1989 (SCE 1989; Akbari 1993). Even though these data were collected years ago, they are still valuable for the purposes of this study because end-use loads are unlikely to have changed significantly relative to the other uncertainties in this study. Berkeley Lab recovered these data and recreated load shapes to be used in current modeling efforts.

Unfortunately, the SCE data only include electrical loads, not natural gas loads. Nor could actual gas load data be found by any other means. Because natural gas is the main fuel used to provide building heat and hot water, two major products of CHP technologies, finding plausible data for these loads was critical for this study. DOE-2, which is a building energy simulation program developed at Berkeley Lab, was used to created these heating loads for the same weather year as the SCE data.

It is critical in this study to resolve the electricity and gas loads into end uses because only some end-use loads can be provided by $\mathrm{CHP}$ technologies. These include refrigeration and building cooling (HVAC) for electrical loads, and hot water and building heating for gas loads. The DER-CAM model was adjusted to meet these end uses with CHP when possible.

\section{B.1 Data Description and Preparation}

The initial version of the SCE electricity load data consisted of a statistical analysis system (SAS) data set containing hourly total load data and some end-use load data for 53 commercial premises in the SCE service territory. For confidentiality reasons, detailed information on the businesses was suppressed, but for most premises, business type, total floor area, conditioned floor area, and a corresponding set of hourly weather data were available.

These data were compiled into a database of total and end-use loads for most premises as follows:

- $\quad$ average weekday by calendar month (1 day type x 12 months)

- $\quad$ average weekend by calendar month (1 day type x 12 months)

Peak day averages, which were used in a previous DER-CAM analysis that examined only total electrical loads were not available for the electrical end-use data. The model was modified to use only week- and weekend day types. For each month of the year two sets of average hourly loads, weekday and weekend, were defined for each end use. For most buildings, electrical end uses, such as refrigeration, cooking, and HVAC, were measured separately. Not every property included data for each end use. Also, in most cases measured end use loads did not add up to the total load given for a specific property. To account for this "missing" electricity, an additional end use was calculated by taking the difference between the sum of the end uses and the total. 
This "Residual" load accounts for electrical end uses that were not measured or for errors in data collection or recording. The end uses monitored are not consistent across all customer sites although the major end uses, such as lighting and HVAC, are always identified. The residual load also includes end uses that were measured in general but were not recorded for a given building. For this study, the "Residual" electrical load is considered an electricity-only load, or one that cannot be met by CHP.

Once the 10 building types analyzed in this study were selected, the DOE-2 model was run for each one to produce natural gas loads by end use. This entailed imputing the correct floor area for each building, choosing the appropriate end-use loads, such as cooking, hot water, and space heating (depending on the building type) and running the program. An output file was then produced, from which the appropriate end-use data were extracted, e.g., "Total Heating Watt" for space heating, or "DHW Heat Fuel Watt" for hot water for the Retail Store. DOE-2 is a complex simulation program, so each building type had to be treated separately. Because of the complexity of the model, the appropriate end-use parameters were not the same for each building. These data were then formatted and averaged into the same monthly format as the electrical loads. For the purposes of this analysis, it was assumed that only the hot-water and space-heat loads could be met by CHP. CHP technologies cannot reduce the gas-only load.

\section{B.2 Additional Estimates}

Some estimations and manipulations to measured data were required where there were missing data or where building types did not correspond to any available measured data. In the later instances, load shapes were constructed from measured data for applicable end uses (such as lighting) and additional energy use by appliances characteristic of that building type (such as washers and dryers for the laundromat). Additionally, for building types with unusual hours of operation (such as 24-hour markets or late-night stores) the early evening loads of measured businesses were extrapolated to include late evening hours.

\section{B.3 Summary of Energy Data and Sources for Customers in the Small Commercial/ Residential Area}

The table below shows the ten customer types in the small commercial/residential area, their energy-use characteristics, building floor area, and data sources for electricity and heat loads.

Table A-1. Energy Load Shape Data Sources

\begin{tabular}{|l|l|l|l|l|}
\hline TYPE & CHARACTERISTICS & AREA $^{\text {a }}\left(\mathbf{m}^{2}\right)$ & ELECTRIC $^{\mathbf{2}}$ & HEAT \\
\hline Residential & Typical & 45 Residences $^{\mathbf{b}}$ & SDG\&E $^{\text {b }}$ & N/A $^{\mathbf{c}}$ \\
\hline & & & & \\
\hline Office 1 & Typical 9-5 hours & 1,492 & SCE & DOE-2 \\
\hline Office 2 & Medical Office (higher load) & 1,010 & SCE & DOE-2 \\
\hline & & & & \\
\hline Retail 1 & Typical 10-6 hours & 3,398 & SCE & DOE-2 \\
\hline Retail 2 & Reg. hours, higher loads & 418 & SCE & DOE-2 \\
\hline Retail 3 & Open Late/ 24 hour & 1,706 & SCE & DOE-2 \\
\hline
\end{tabular}




\begin{tabular}{|l|l|l|l|l|}
\hline TYPE & CHARACTERISTICS & AREA $^{\text {a }}\left(\mathbf{m}^{2}\right)$ & ELECTRIC & HEAT \\
\hline Retail 4 & Reg. hours, high heat loads & 741 & SCE & DOE-2 $^{\text {d }}$ \\
\hline & & & & \\
\hline Restaurant & Lunch peak, open late & 710 & SCE & DOE-2 \\
\hline & & & & \\
\hline Hospital & 24 hr. emergency & 20,707 & SCE + Est. $^{\text {e }}$ & DOE-2 $^{\text {( }}$ \\
\hline Laundromat & 50 washers, 40 dryers & 444 & SCE + Est. & Est. $^{\text {g }}$ \\
\hline
\end{tabular}

a. Site area calculated by GIS. This is the total area for all buildings classified as the corresponding customer type. This value includes all area within the property line and therefore does not account for parking or other open space that is contained within building property but does not contribute to building energy use. These values are therefore reduced by 25 percent to correct for the space that does not consume energy.

b. Publicly available data for SDG\&E customers averaged over all households. Data are from 19941996.

c. It is assumed that the cost of retrofitting individual residences is prohibitive.

d. DOE-2 requires a special input for higher heat loads of the highest hot water usage throughout one day. This value is calculated from the measured annual hot water use of a hair salon as 77.4 MMBtu.

e. Hospital measured data were not available divided into end use. Therefore, the cooling load was calculated from the total load based on the hourly percentage of total load it represented in a simulated run by DOE-2.

f. Electricity use from washers and dryers was added to lighting and plug loads from a similar business type.

g. Hot water use of washers was estimated.

The table below shows the individual energy characteristics of each of the ten customer types in the commercial/residential area. The energy characteristics of the total $\mu$ Grid shown in the last row are not necessarily a sum of the characteristics of the individual customers. For example, the peak loads of the individual customers do not occur at the same times of the day or year, and will therefore not sum to the total peak load of the $\mu$ Grid.

Table A-2. Energy Characteristics of Individual Customers

\begin{tabular}{|l|l|l|l|l|l|}
\hline \multicolumn{1}{|c|}{ TYPE } & $\begin{array}{c}\text { \# OF } \\
\text { SITES }\end{array}$ & $\begin{array}{c}\text { TOTAL ANNUAL } \\
\text { ELECTRICITY } \\
(\text { MWh })\end{array}$ & $\begin{array}{c}\text { PEAK } \\
\text { LOAD } \\
(\mathbf{k W})\end{array}$ & PEAK HOUR & $\begin{array}{c}\text { LOAD } \\
\text { FACTOR }\end{array}$ \\
\hline Residential & 45 & 242 & 50 & December Weekend 17:00 & $56 \%$ \\
\hline & 6 & 234 & 72 & July Weekday 13:00 & $32 \%$ \\
\hline Office & 6 & 242 & 87 & July Weekday 13:00 & $27 \%$ \\
\hline $\begin{array}{l}\text { Medical } \\
\text { Office }\end{array}$ & 1 & & & & \\
\hline & & 647 & 172 & July Weekend 15:00 & $43 \%$ \\
\hline Retail 1 & 4 & 111 & 26 & July Weekend 15:00 & $48 \%$ \\
\hline Retail 2 & 2 & 256 & 54 & October Weekday 18:00 & $53 \%$ \\
\hline Retail 3 & 2 & 141 & 37 & July Weekend 15:00 & $43 \%$ \\
\hline Retail 4 & 4 & & 69 & July Weekend 19:00 & $60 \%$ \\
\hline & & 366 & &
\end{tabular}




\begin{tabular}{|l|l|l|l|l|l|}
\hline \multicolumn{1}{|c|}{ TYPE } & $\begin{array}{c}\text { \# OF } \\
\text { SITES }\end{array}$ & $\begin{array}{c}\text { TOTAL ANNUAL } \\
\text { ELECTRICITY } \\
(\mathbf{M W h})\end{array}$ & $\begin{array}{c}\text { PEAK } \\
\text { LOAD } \\
(\mathbf{k W})\end{array}$ & \multicolumn{1}{c|}{ PEAK HOUR } & $\begin{array}{c}\text { LOAD } \\
\text { FACTOR }\end{array}$ \\
\hline Hospital & 1 & 2449 & 406 & January Weekend 8:00 & $69 \%$ \\
\hline Laundromat & 1 & 67 & 18 & June Weekday 18:00 & $42 \%$ \\
\hline Total & & 2516 & 886 & July Weekday 15:00 & $60 \%$ \\
\hline
\end{tabular}




\section{Appendix C: DER-CAM Mathematical Model}

This appendix describes the most recent version of the Distributed Energy Resources Customer Adoption Model (DER-CAM). This version of the model has been programmed in General Algebraic Modeling System (GAMS). ${ }^{1}$ DER-CAM inputs, outputs, objective function, and some key assumptions are described in the following subsection, and the mathematical formulation of the model is presented.

\section{C.1 Model Description}

In a previous Berkeley Lab report prepared for the California Energy Commission, the first spreadsheet version of the Customer Adoption Model was described and implemented (Marnay et al., 2000); a subsequent report described programming of the model in GAMS (Marnay et al., 2001). The model's objective function, which has not changed, is "to minimize the cost of supplying electricity to a specific customer by optimizing the installation of distributed generation and the self-generation of part or all of its electricity."2 In other words, the focus of this work continues to be strictly economic. To achieve this objective, the following issues must be addressed:

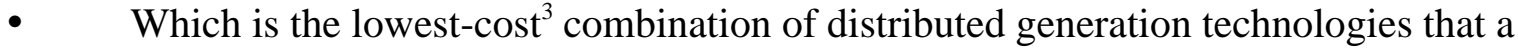
specific customer can install?

- What is the appropriate level of installed capacity of these technologies that minimizes cost?

- How should the installed capacity be operated so as to minimize the total customer bill for meeting its electricity load?

It is assumed that the customer desires to install distributed generation to minimize the cost of electricity consumed on site. Consequently, it should be possible to determine the technologies and capacity the customer is likely to install and to predict when the customer will be selfgenerating and/or transacting with the grid.

Key inputs into the model are:

- $\quad$ the customer's end-use load profiles (space heat, hot water, gas only, cooling, and electricity only)

- $\quad$ the customer's default San Diego Gas and Electric (SDG\&E) tariff

- $\quad$ the capital, operating and maintenance (O\&M), and fuel costs of the various available technologies, together with the interest rate on customer investment

\footnotetext{
${ }^{1}$ GAMS is a proprietary software product used for high-level modeling of mathematical programming problems. It is owned by the GAMS Development Corporation (http://www.gams.com) and is licensed to Berkeley Lab.

2 Marnay et al., 2000.

${ }^{3}$ Here, costs include turnkey (purchase, delivery, and installation) costs as well as fixed and variable operational costs.
} 
- the basic physical characteristics of alternative generating technologies, including the thermal-electric ratio that determines how much residual heat is available as a function of generator electric output

Outputs to be determined by the optimization model are:

- the DG technology or combination of technologies to be installed

- the capacity of each technology to be installed

- when and how much of the capacity installed will be running

- $\quad$ the total cost of supplying electricity

The key assumptions are:

- $\quad$ Customer decisions are made based only on direct economic criteria. In other words, the only possible benefit is a reduction in the customer's electricity bill.

- $\quad$ No deterioration in output or efficiency during the lifetime of the equipment is considered. Furthermore, start-up and other ramping constraints are not included.

- $\quad$ Reliability and power quality benefits, as well as economies of scale in O\&M costs for multiple units of the same technology are not taken into account.

- $\quad$ Possible reliability or power quality improvements accruing to customers are not considered.

\section{C.2 Mathematical Formulation}

This section describes in detail the core mathematical problem solved by DER-CAM. First, the names of all input parameters are listed. Second, the decision variables (i.e. the model outputs) are defined. And third, the mathematical formulation used to solve the optimization problem is presented for two possible tariff options.

\section{C.2.1 Input Parameters}

Customer Data

\begin{tabular}{|l|l|}
\hline Name & Description \\
\hline Cload $_{1, \mathrm{~m}, \mathrm{t}, \mathrm{h}}$ & $\begin{array}{l}\text { Customer load in } \mathrm{kW} \text { during hour } h \text {, day type } t \text {, and month } m \text { for end } \\
\text { use } l \text { (Hot water, Space heating, Gas only, Cooling, Electricity only). }\end{array}$ \\
\hline
\end{tabular}

CHP and Absorption Cooling Technologies Data

\begin{tabular}{|l|l|}
\hline Name & Description \\
\hline CHPcapcost $i$ & Capital cost of CHP technology $i$ \\
\hline CHP cost operating $i$ & Operating cost per kWh electric produced $(\$ / \mathrm{kWh})$ for technology $i$ \\
\hline CHPom fixed $i$ & Fixed operating and maintenance costs of technology $i(\$ / \mathrm{kW})$ \\
\hline TE ratio $i$ & $\begin{array}{l}\text { Thermal output }(\mathrm{kW} \text { th) per } \mathrm{kW} \text { electric produced of CHP technology } i . \\
\text { This coefficient multiplied by GenL }(\text { defined below under decision } \\
\text { variables) determines how much residual heat is available }\end{array}$ \\
\hline
\end{tabular}


Other parameters

\begin{tabular}{|l|l|}
\hline Name & Description \\
\hline IntRate & Interest rate on DER investments $(\%)$ \\
\hline StandbyC & $\begin{array}{l}\text { Standby charge in \$/kW/month that SDG\&E currently applies to its } \\
\text { customers with autonomous generation }\end{array}$ \\
\hline Solar $_{m, h}$ & $\begin{array}{l}\text { Average solar insulation as a percentage of the maximum possible } \\
\text { during hour } h \text { and month } m(\%)\end{array}$ \\
\hline NGprice $_{m, t, h}$ & Price of natural gas during month $m$, day type $t$, hour $h(\$ / \mathrm{kWh})$ \\
\hline ConversionEfficiencyNG & Efficiency of converting purchased natural gas to useable heat $(\%)$ \\
\hline $\begin{array}{l}\text { Conversion factor from } \\
k W \text { electrical cooling to } \\
k W \text { thermal cooling }\end{array}$ & $\begin{array}{l}\text { Efficiency of converting from absorption cooling capacity produced in } \\
\text { the form of waste heat }(\mathrm{kWth}) \text { to a reduction in the use of electric } \\
\text { compressor cooling }(\mathrm{kWe})\end{array}$ \\
\hline
\end{tabular}

SDG\&E Data

\begin{tabular}{|c|c|}
\hline Name & Description \\
\hline RTPower $_{s, p}$ & $\begin{array}{l}\text { Regulated demand charge under the default tariff for season }{ }^{5} s \text { and } \\
\text { period }^{6} p(\$ / \mathrm{kW})\end{array}$ \\
\hline RTEnergy $y_{m, t, h}$ & $\begin{array}{l}\text { Regulated tariff for energy purchases during hour } h \text {, type of day } t \text {, and } \\
\text { month } m(\$ / \mathrm{kWh})\end{array}$ \\
\hline RTCCharge & Regulated tariff customer charge $(\$)$ \\
\hline RTFCharge & Regulated tariff facilities charge $(\$ / \mathrm{kW})$ \\
\hline RTGPower $_{s, p}$ & $\begin{array}{l}\text { Regulated demand gas charge under the default tariff for season }{ }^{7} s \text { and } \\
\text { period }^{8} p(\$ / \mathrm{kW})\end{array}$ \\
\hline RTGEnergy ${ }_{m, t, h}$ & $\begin{array}{l}\text { Regulated tariff for gas purchases during hour } h \text {, type of day } t \text {, and month } \\
m(\$ / \mathrm{kWh})\end{array}$ \\
\hline RTGCCharge & Regulated tariff customer charge for gas $(\$)$ \\
\hline
\end{tabular}

Distributed Energy Resource Technologies Information

\begin{tabular}{|c|c|}
\hline Name & Description \\
\hline $\operatorname{DERmaxp}_{i}$ & Nameplate power rating of technology $i(\mathrm{~kW})$ \\
\hline DERlifetime $_{i}$ & Expected lifetime of technology $i$ (years) \\
\hline DERcapcost $_{i}$ & Overnight capital cost of technology $i(\$ / \mathrm{kW})$ \\
\hline DEROMfix & Fixed annual operation and maintenance costs of technology $i(\$ / \mathrm{kW})$ \\
\hline DEROMvar & Variable operation and maintenance costs of technology $i(\$ / \mathrm{kWh})$ \\
\hline
\end{tabular}

\footnotetext{
${ }^{4}$ Only applicable to customers selling power to the utility, which is not relevant to this report.

${ }^{5}$ There are two seasons: summer and winter.

${ }^{6}$ There are three different time-of-use periods (for tariff purposes only): on-peak, mid-peak, and off-peak.

${ }^{7}$ There are two seasons: summer and winter.

${ }^{8}$ There are three different time-of-use periods (for tariff purposes only): on-peak, mid-peak, and off-peak.
} 


\begin{tabular}{|l|l|}
\hline Name & Description \\
\hline DERCostkWh & Production cost of technology $i(\$ / \mathrm{kWh})$ \\
\hline DERhours & \\
\hline
\end{tabular}

C.2.2 Decision Variables

\begin{tabular}{|c|c|}
\hline Name & Description \\
\hline InvGen $_{i}$ & Number of units of technology $i$ installed by the customer \\
\hline$G e n L_{l, l, i, t, t, h}$ & $\begin{array}{l}\text { Generated power by technology } i \text { during hour } h \text {, type of day } t \text {, and month } \\
m \text { to supply the customer's load } l(\mathrm{~kW})\end{array}$ \\
\hline Heat $_{l, i, m, t, h}$ & $\begin{array}{l}\text { Residual heat produced by technology } i \text { during hour } h \text {, type of day } t \text {, and } \\
\text { month } m \text { to supply the customer's load } l(\mathrm{~kW}) \text { when the load is either } \\
\text { Hot Water or Space Heating }\end{array}$ \\
\hline $\operatorname{Cool}_{l, l, m, t, h}$ & $\begin{array}{l}\text { Residual heat produced by technology } i \text { during hour } h \text {, type of day } t \text {, and } \\
\text { month } m \text { to supply the customer's load } l(\mathrm{~kW}) \text { when the load is either } \\
\text { Refrigeration or HVAC }\end{array}$ \\
\hline Dump $_{. l, i, m, t, h}$ & $\begin{array}{l}\text { Dummy variable that allows more residual heat to be produced than is } \\
\text { demanded on site. }\end{array}$ \\
\hline$G e n X_{i, m, t, h}$ & $\begin{array}{l}\text { Generated power by technology } i \text { during hour } h \text {, type of day } t \text {, and month } \\
m \text { to sell in the wholesale market }(\mathrm{kW})\end{array}$ \\
\hline DRLoad $_{l, m, t, h}$ & $\begin{array}{l}\text { Residual customer load } l \text { (electricity purchased from the distribution } \\
\text { company by the customer) during hour } h \text {, type of day } t \text {, and month } m \\
(\mathrm{~kW})\end{array}$ \\
\hline DRGLoad $_{l, m, t, h}$ & $\begin{array}{l}\text { Residual customer load } l \text { (natural gas purchased from the distribution } \\
\text { company by the customer) during hour } h \text {, type of day } t \text {, and month } m \\
(\mathrm{~kW})\end{array}$ \\
\hline
\end{tabular}

\section{C.2.3 Mathematical Formulation}

The equations listed below are the DER-CAM objective function and the constraints to the objective function that ensure realistic operation of generator equipment. A description of each equation is listed at the end of this section. 
Objective Function

$$
\begin{aligned}
& \min \\
& \operatorname{InvGen}_{i} \text {, } \\
& \operatorname{GenL}_{l, i, m, t, h} \text {, } \\
& \text { GenX } X_{i, m, t, h} \\
& \sum_{m} \text { RTFCharge } \cdot \max \left(\text { DRLoad }_{m, t, h}\right)+\sum_{m} \text { RTCCharge } \\
& +\sum_{m} R T G F C h a r g e \cdot \max \left(\text { DRGLoad }_{m, t, h}\right)+\sum_{m} R T G C \text { Charge } \\
& +\sum_{s} \sum_{m \in s} \sum_{p} \text { RTPower }_{s, p} \cdot \max \left(\text { DRLoad }_{m,(t, h) \in p}\right) \\
& +\sum_{s} \sum_{m \in s} \sum_{p} \text { RTGPower }_{s, p} \cdot \max \left(\text { DRGLoad }_{l, m,(t, h) \in p}\right) \\
& +\sum_{l} \sum_{i} \sum_{m} \sum_{t} \sum_{h}\left(G e n L_{l, i, m, t, h}+G e n X_{i, m, t, h}\right) \cdot D E R \operatorname{Cos} t k W h_{i} \\
& +\sum_{l} \sum_{i} \sum_{m} \sum_{t} \sum_{h}\left(\text { GenL }_{l, i, m, t, h}+\text { GenX }_{i, m, t, h}\right) \text { DEROMvar }{ }_{i} \\
& +\sum_{i} \operatorname{InvGen}_{i} \cdot\left(\text { DERcapcost }_{i}+\text { DEROMfix }_{i}\right) \cdot \text { AnnuityF } \\
& +\sum_{m} \sum_{i} \text { InvGen }_{i} \cdot \text { DERmaxp }_{i} \cdot \operatorname{StandbyC} \\
& -\sum_{l} \sum_{i} \sum_{m} \sum_{t} \sum_{h}\left(\operatorname{GenX}_{i, m, t, h} \cdot \operatorname{IEM}_{m, t, h}\right)
\end{aligned}
$$

Constraints to Objective Function

Cload $_{l, m, t, h}=\sum_{i}$ Heat $_{l, i, m, t, h}+$ DRGLoad $_{l, m, t, h} \forall_{l, m, t, h}$ if $l \in\{$ Heating $\}$

Space and water heating loads

Cload $_{l, m, t, h}=\sum_{i} \operatorname{GenL}_{l, i, m, t, h}+\sum_{i} \operatorname{Cool}_{l, i, m, t, h}+$ DRLoad $_{l, m, t, h} \forall_{l, m, t, h}$ if $l \in\left\{\right.$ Cooling $^{\text {(2b) }}$

Cooling loads

Cload $_{l, m, t, h}=$ DRGLoad $_{l, m, t, h} \forall_{l, m, t, h}$ if $l \in\{$ Cooking $\}$

Gas only loads

Cload $_{l, m, t, h}=\sum_{i}$ GenL $_{l, i, m, t, h}+$ DRLoad $_{l, m, t, h} \forall_{l, m, t, h}$ if $l \in\{$ Electrical $\}$

Electrical loads

$\sum_{l} \operatorname{GenL}_{l, i, m, t, h}+\operatorname{GenX}_{i, m, t, h} \leq \operatorname{InvGen}_{i} \cdot \operatorname{DER\operatorname {max}p_{i}} \forall_{i, m, t, h}$ 


$$
\begin{aligned}
& \text { GenX }_{i, m, t, h}=0 \text { if } \sum_{l} \sum_{i} \text { GenL }_{l, i, m, t, h}<\sum_{l} \operatorname{Cload}_{l, m, t, h} \forall_{i, m, t, h} \text { if } l \in\{\text { Electrical }\}_{\text {(4) }} \\
& \text { Annuity } F=\frac{\text { IntRate }}{\left(1-\frac{1}{\left(1+\text { IntRate }^{\text {DERlifetime }_{i}}\right.}\right)} \\
& \sum_{h} \operatorname{GenL}_{l, j, m, t, h}+\operatorname{GenX}_{j, m, t, h} \leq \operatorname{InvGen}_{j} \cdot \operatorname{DER} \max p_{j} \cdot \operatorname{Solar}_{m, h} \forall_{m, t, h} \text { if } j \in\{P V\} \\
& \sum_{l} \sum_{j}\left(\text { Heat }_{l, j, m, t, h}+\operatorname{Cool}_{l, j, m, t, h}+\operatorname{Dump}_{l, j, m, t, h}\right)=\sum_{l} \sum_{j}\left(\left(\text { GenL }_{l, j, m, t, h}+\text { GenX }_{j, m, t, h}\right) \cdot \text { TEratio }_{j}\right) \forall_{m, t, h}
\end{aligned}
$$

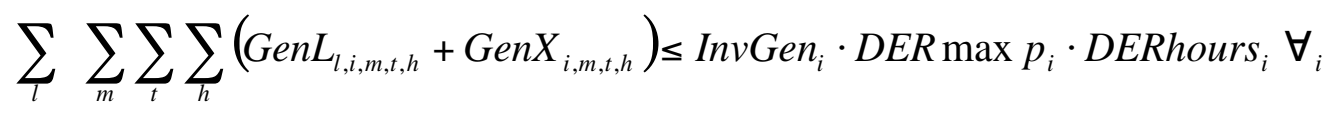

- $\quad$ Equation (1) is the objective function, which says that the customer will try to minimize total cost, consisting of: total facilities and customer charges, total monthly demand charges, total on-site generation fuel and O\&M costs, total DER investment cost, total standby charges, and minus the revenues generated by any energy sales to the macrogrid.

- $\quad$ Equation (2) enforces energy balance for heating, cooling, gas only, and electrical loads.

- $\quad$ Equation (3) enforces the on-site generating capacity constraint.

- $\quad$ Equation (4) prohibits the customer from buying and selling energy at the same time.

- Equation (5) annualizes the capital cost of owning on-site generating equipment.

- In Equation (6), if the customer is operating any photovoltaic cells, their actual energy output is their rated capacity scaled down by the amount of solar insulation.

- $\quad$ Equation (7) constrains the maximum amount of residual heat available for cooling or heating depending on the operation level of the micro turbine. This ensures that residual heat is produced by on-site electricity generation. In addition, electricity is not produced simply to provide waste heat. In other words, the production of waste heat is limited by the electrical load.

- In Equation (8), the maximum total amount of energy that any given generator $i$ can produce throughout the year is effectively restricted by the parameter DERhours . This $_{\text {. Th }}$ constraint is intended mainly to prevent the diesel generators from operating more than the maximum legal allowable number of hours. 


\section{Appendix D: DER-CAM Technology Database}

\begin{tabular}{|c|c|c|c|c|c|c|c|c|c|c|c|c|c|}
\hline & Name & DER Type & Source & Nameplate & lifetime & $\$ / \mathrm{kW}$ cost & $\$ / \mathrm{kW}$ cost & OMFix & OMVar & Lev Cost & Heat Rate & NOx & PM \\
\hline & & & & $\mathbf{k W}$ & (a) & FOB cost & Turnkey cost & $\$ / \mathbf{k W} / \mathbf{a}$ & $\$ / \mathbf{k W h}$ & $\mathbf{c} / \mathbf{k W h}$ & $\mathrm{kJ} / \mathbf{k W h}$ & $\mathrm{g} / \mathbf{k W h}$ & $\mathrm{g} / \mathbf{k W h}$ \\
\hline 1 & MTL-C-30 & MT & SCE & 30 & 12.5 & 1200 & 1333 & 119 & in Fix O\&M & 12.14 & 12,186 & & \\
\hline 3 & MT-HW-75 & MT & SCE & 75 & 12.5 & 700 & 753 & $0.5 \mathrm{c} / \mathrm{kWh}$ & in Fix O\&M & 10.56 & 11,373 & 0.238 & \\
\hline 4 & PAFC-O-200 & PAFC & TAG & 200 & 12.5 & 3500 & PR & PR & PR & 13.68 & PR & PR & \\
\hline 5 & DE-K-15 & Diesel Backup & manufacturer & 15 & 12.5 & 878 & 2257 & 26.5 & 0.000033 & N/A & 0 & & \\
\hline 6 & DE-K-30 & Diesel Backup & manufacturer & 30 & 12.5 & 473 & 1290 & 26.5 & 0.000033 & 5.51 & 11,887 & 8.17 & 0.54 \\
\hline 7 & DE-K-60 & Diesel Backup & manufacturer & 60 & 12.5 & 290 & 864 & 26.5 & 0.000033 & 6.30 & 11,201 & 11.57 & 0.54 \\
\hline 8 & DE-K-105 & Diesel Backup & manufacturer & 105 & 12.5 & 212 & 690 & 26.5 & 0.000033 & 5.48 & 10,581 & 12.25 & 0.54 \\
\hline 9 & DE-K-200 & Diesel Backup & manufacturer & 200 & 12.5 & 170 & 514 & 26.5 & 0.000033 & 5.20 & 11,041 & 8.85 & 0.27 \\
\hline 10 & DE-K-350 & Diesel Backup & manufacturer & 350 & 12.5 & 156 & 414 & 26.5 & 0.000033 & 4.61 & 10,032 & 8.16 & 0.68 \\
\hline 11 & DE-K-500 & Diesel Backup & manufacturer & 500 & 12.5 & 166 & 386 & 26.5 & 0.000033 & 4.65 & 10,314 & 8.57 & 0.16 \\
\hline 12 & DE-C-7 & Diesel Backup & manufacturer & 7.5 & 12.5 & 213 & 627 & 26.5 & 0.000033 & N/A & 10,458 & & \\
\hline 13 & DE-C-20 & Diesel Backup & manufacturer & 20 & 12.5 & 440 & 1188 & 26.5 & 0.000033 & 7.48 & 12,783 & & 0.54 \\
\hline 14 & DE-C-40 & Diesel Backup & manufacturer & 40 & 12.5 & 350 & 993 & 26.5 & 0.000033 & 7.05 & 11,658 & & 0.54 \\
\hline 15 & DE-C-100 & Diesel Backup & manufacturer & 100 & 12.5 & 180 & 599 & 26.5 & 0.000033 & 5.45 & 10,287 & & 0.54 \\
\hline 16 & DE-C-200 & Diesel Backup & manufacturer & 200 & 12.5 & 135 & 416 & 26.5 & 0.000033 & 4.94 & 9,944 & & 0.27 \\
\hline 17 & DE-C-300 & Diesel Backup & manufacturer & 300 & 12.5 & 127 & 357 & 26.5 & 0.000033 & 5.14 & 10,287 & & 0.41 \\
\hline 18 & DE-C-500 & Diesel Backup & manufacturer & 500 & 12.5 & 136 & 318 & 26.5 & 0.000033 & 5.42 & 9,327 & & 0.16 \\
\hline 19 & GA-K-25 & Gas Backup & manufacturer & 25 & 12.5 & 522 & 1730 & 26.5 & 0.000033 & 10.42 & 15,596 & & \\
\hline 20 & GA-K-55 & Gas Backup & manufacturer & 55 & 12.5 & 290 & 970 & 26.5 & 0.000033 & 7.55 & 12,997 & & \\
\hline 21 & GA-K-100 & Gas Backup & manufacturer & 100 & 12.5 & 259 & 833 & 26.5 & 0.000033 & 9.18 & 15,200 & & \\
\hline 22 & GA-K-215 & Gas Backup & manufacturer & 215 & 12.5 & 416 & 1185 & 26.5 & 0.000033 & 7.15 & 13,157 & 6.05 & \\
\hline 23 & GA-K-500 & Gas Backup & manufacturer & 500 & 12.5 & 408 & 936 & 26.5 & 0.000033 & 7.33 & 12,003 & 25.29 & \\
\hline 24 & WD-1 & Wind & Bergey Windpower & 1 & 12.5 & 3920 & 8920 & 3.8 & 0 & 39.85 & & & \\
\hline 25 & WD-10 & Wind & Bergey Windpower & 10 & 12.5 & 2805 & 6055 & 5.7 & 0 & 27.05 & & & \\
\hline 26 & PV-5 & $\mathrm{PV}$ & Jeff Oldman, Real Goods & 5 & 20 & 7150 & 8650 & 14.3 & 0 & 55.23 & & 0.0 & 0.0 \\
\hline 27 & PV-20 & $\mathrm{PV}$ & Jeff Oldman, Real Goods & 20 & 20 & 5950 & 7450 & 14.3 & 0 & 47.56 & & 0.0 & 0.0 \\
\hline 28 & PV-50 & $\mathrm{PV}$ & Jeff Oldman, Real Goods & 50 & 20 & 5175 & 6675 & 5 & 0 & 42.62 & & 0.0 & 0.0 \\
\hline 29 & PV-100 & $\mathrm{PV}$ & Jeff Oldman, Real Goods & 100 & 20 & 5175 & 6675 & 2.85 & 0 & 42.62 & & 0.0 & 0.0 \\
\hline
\end{tabular}




\section{Appendix E: San GIS Parcel Layer Metadata}

This appendix includes metadata available in SanGIS datasets for the individual building parcels used in this study. These metadata include information such as building address, owner information, assessed land value, and building use at time of survey. It can be seen by the characterizations of building use that the information is often not specific enough to conduct a detailed energy end-use analysis. Additional information regarding SanGIS data is listed at the end of this appendix.

\section{Table A-3. SanGIS parcel metadata}

\begin{tabular}{|l|l|}
\hline \multicolumn{1}{|c|}{ Attribute } & \multicolumn{1}{c|}{ Description } \\
\hline Area & Polygon area as calculated by software \\
\hline Perimeter & Polygon perimeter as calculated by software \\
\hline Parcel & Software internal ID \\
\hline Parcel_ID & Software internal ID \\
\hline Parcelid & SanGIS internal Parcel ID Number \\
\hline APN & Assessor Parcel Number (10 digit) \\
\hline APN_8 & Assessor Parcel Number (8 digit) \\
\hline Name1 & Owner Name 1 \\
\hline Name2 & Owner Name 2 \\
\hline Name3 & Owner Name 3 \\
\hline Fractint & Fractional Interest \\
\hline Addr1 & Mailing Address 1 \\
\hline Addr2 & Mailing Address 2 \\
\hline Addr3 & Mailing Address 3 \\
\hline Addr4 & Mailing Address 4 \\
\hline Zipcode & Mailing Zip Code \\
\hline Sitename & Site Name \\
\hline Legldesc & Legal Description \\
\hline Asesland & Assessed Land value \\
\hline Asesimp & Assessed Improvement value \\
\hline Asestotal & Total Assessed value \\
\hline
\end{tabular}




\begin{tabular}{|c|c|}
\hline Acreage & Parcel acreage \\
\hline Taxstat & $\begin{array}{l}\text { Tax Status: } \\
\mathrm{N}=\quad \text { Nontaxable } \\
\mathrm{T}=\quad \text { Taxable }\end{array}$ \\
\hline Ownerocc & Owner Occupied (Y or $\mathrm{N})$ \\
\hline Tranum & Tax Rate Area Number \\
\hline Assess_Zone & \begin{tabular}{ll}
\multicolumn{2}{l}{ Assessment Zone Code: } \\
$0=$ & Unzoned \\
$1=$ & Single family residential (R-1) \\
$2=$ & Minor multiple (R-2) \\
$3=$ & Restricted multiple (R-3) \\
$4=$ & Multiple residential (R-4) \\
$5=$ & Restricted commercial \\
$6=$ & Commercial \\
$7=$ & Industrial (M zone) \\
$8=$ & Agricultural \\
$9=$ & Special and/or misc.
\end{tabular} \\
\hline Asses_lan & $\begin{array}{l}\text { Assessment Land-use Code: } \\
07=\quad \text { Timeshare } \\
09=\quad \text { Mobilehome } \\
10=\quad \text { Vacant residential } \\
11=\quad \text { Single family residence } \\
12=\quad \text { Duplex or double } \\
13=\quad \text { Multiple } 2 \text { to } 4 \text { units or } 2 \text { houses } \\
14=\quad \text { Multiple } 5 \text { to } 15 \text { units (res) } \\
15=\quad \text { Multiple } 16 \text { to } 60 \text { units }(\mathrm{com}) \\
16=\quad \text { Multiple } 61 \text { units and up }(\mathrm{com}) \\
17=\quad \text { Condominium } \\
18=\quad \text { Co-Op } \\
19=\quad \text { Miscellaneous } \\
10=\quad \text { Vacant commercial } \\
21=\quad 1 \text { to } 3 \text { story misc. store bldgs } \\
22=\quad 4 \text { story } \& \text { up office/store bldgs } \\
23=\quad \text { Regional shopping center } \\
24=\quad \text { Community shopping center } \\
25=\quad \text { Neighborhood shopping center } \\
26=\quad \text { Hotel, motel } \\
27=\quad \text { Service station } \\
28=\quad \text { Offices/medical,dental,veterinary } \\
29=\quad \text { Rest home/convalescent hospital } \\
30=\quad \text { Office condominiums }\end{array}$ \\
\hline
\end{tabular}




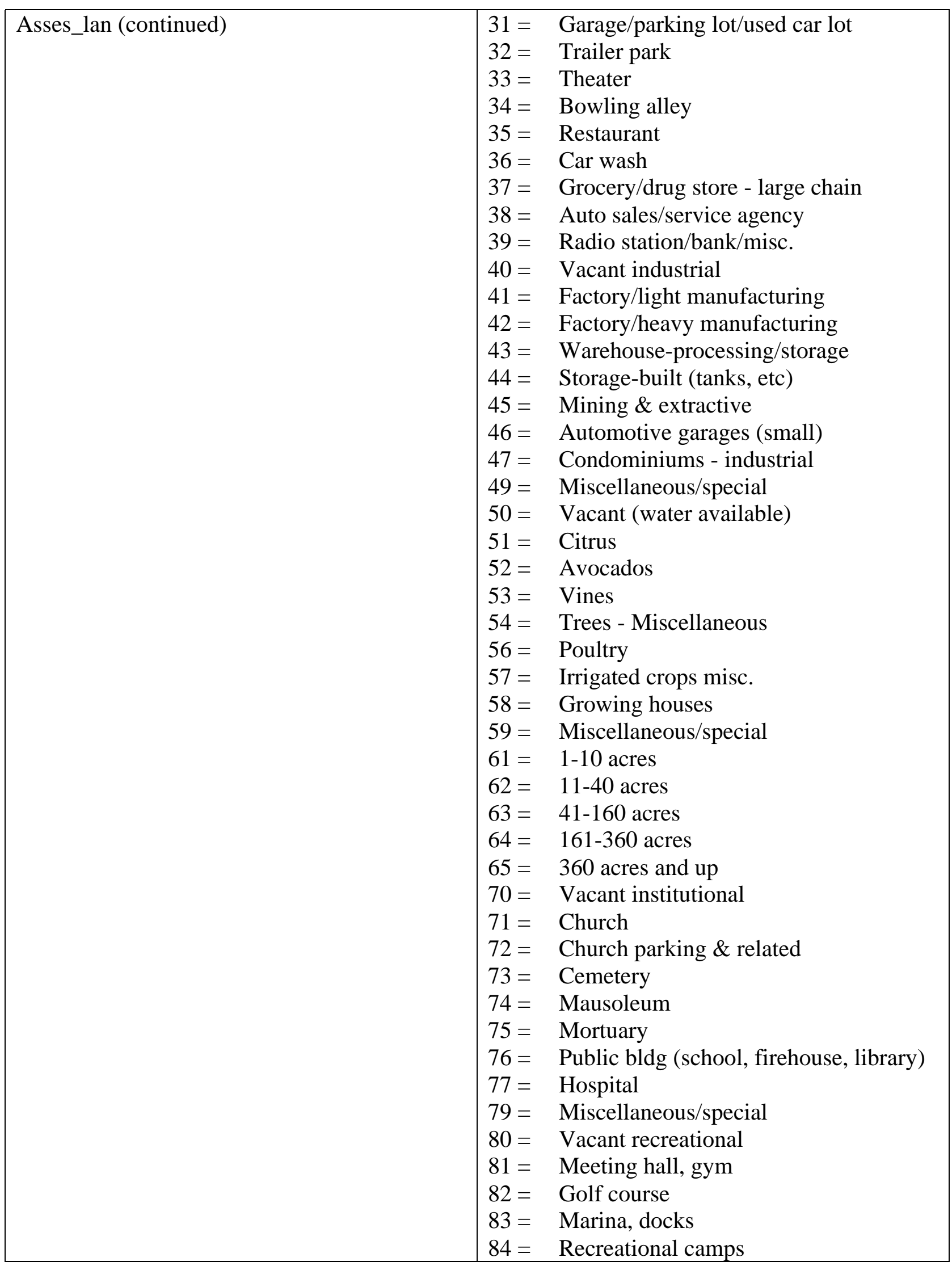




\begin{tabular}{|c|c|}
\hline Asses_lan (continued) & $\begin{array}{ll}86= & \text { Open space easements } \\
88= & \text { Agricultural preserve (under contract) } \\
89= & \text { Miscellaneous/special } \\
90= & \text { Vacant taxable }- \text { gov owned property } \\
91= & \text { Improved taxable }- \text { gov owned property }\end{array}$ \\
\hline$\overline{\text { Submap }}$ & Subdivision Map Number \\
\hline Unitqty & Number of dwelling units \\
\hline Ruisnmbr & Site address number \\
\hline Ruisfrac & Site address fraction \\
\hline Ruisunit & Site address unit \\
\hline Ruispdir & Site address prefix direction \\
\hline Ruisname & Site address road name \\
\hline Ruissfx & Site address suffix \\
\hline Ruisjur & 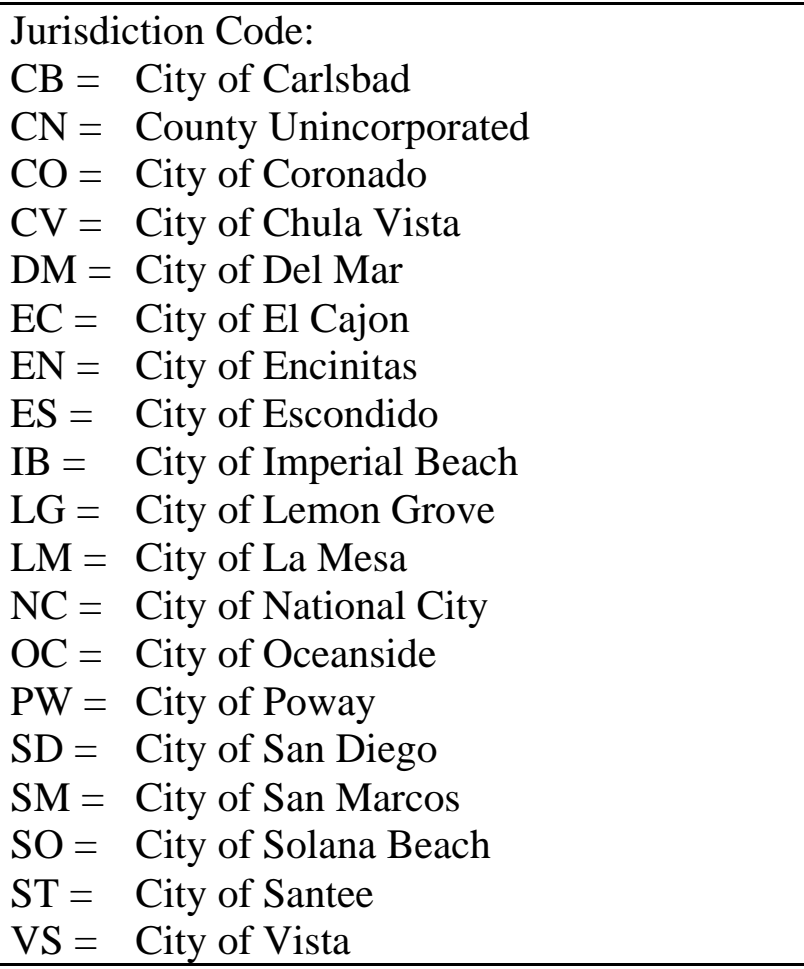 \\
\hline Ruiszip & Site address zip code \\
\hline Parjur & Jurisdiction from municipal layer overlay \\
\hline X_coord & X Coordinate for approximate parcel center \\
\hline Y_coord & Y Coordinate for approximate parcel center \\
\hline
\end{tabular}


Additional Characteristics of San GIS data:

Description: Parcel polygons

Extent: San Diego County

Data Type: Shape file

Feature Type: Polygon

Datum: NAD83

Projection: California State Plane

Zone: VI (3401 in ArcInfo)

Units: Feet

Precision: Double

Positional Accuracy: +/- 10 feet

Source: County Assessor/SDG\&E

Update Frequency: Daily 


\section{Appendix F: San Diego Zoning Noise Ordinance}

Section 59.5.0401 of the San Diego zoning code states the following in regards to sound level limits:

A. It shall be unlawful for any person to cause noise by any means to the extent that the onehour average sound level exceeds the applicable limit given in the following table, at any location in the City of San Diego on or beyond the boundaries of the property on which the noise is produced. The noise subject to these limits is that part of the total noise at the specified location that is due solely to the action of said person.

Table A-4. Applicable Noise Limits

\begin{tabular}{|l|l|l|}
\hline Land-use Zone & Time of Day & $\begin{array}{l}\text { One-Hour } \\
\text { Average Sound Level } \\
\text { (decibels) }\end{array}$ \\
\hline 1. Residential: & 7 a.m. to 7 p.m. & 50 \\
All R-1 & 7 p.m. to 10 p.m. & 45 \\
& 10 p.m. to 7a.m. & 40 \\
\hline 2. All R-2 & 7 a.m. to 7 p.m. & 55 \\
& 7 p.m. to 10 p.m. & 50 \\
& 10 p.m. to 7a.m. & 45 \\
\hline 3. R-3, R-4 and all other Residential & 7 a.m. to 7 p.m. & 60 \\
& 7 p.m. to 10 p.m. & 55 \\
& 10 p.m. to 7a.m. & 50 \\
\hline 4. All Commercial & 7 a.m. to 7 p.m. & 65 \\
& 7 p.m. to 10 p.m. & 60 \\
& 10 p.m. to 7a.m. & 60 \\
\hline 5. Manufacturing all other Industrial, & Any time & 75 \\
including Agricultural and & & \\
Extractive Industry & & \\
\hline
\end{tabular}

B. The sound level limit at a location on a boundary between two zoning districts is the arithmetic mean of the respective limits for the two districts. Permissible construction noise level limits shall be governed by Sections 59.5.0404 of this article.

C. Fixed-location public utility distribution or transmission facilities located on or adjacent to a property line shall be subject to the noise level limits of Part A. of this section, measured at or beyond six feet from the boundary of the easement upon which the equipment is located.

D. This section does not apply to firework displays authorized by permit from the Fire Department.

E. This section does not apply to noise generated by helicopters at heliports or helistops authorized by a conditional use permit, nor to any roller coaster operated on City-owned parkland. (Amended 9-11-89 . by O-17337 NS. ) 


\section{Appendix G: San Diego Gas \& Electric Time-of-Use (TOU) Tariff Rates}

The table below shows the commercial time-of-use tariff rates used as a cost input to the DERCAM mathematical model. The cost of installing and operating on-site generation is compared with the utility electricity price to determine the lowest-cost solution for a representative year.

Table A-5. SDG\&E time-of-use tariff rates

\begin{tabular}{|l|l|l|l|}
\hline MONTHS & HOURS & $\begin{array}{l}\text { Demand } \\
\text { Charge } \\
(\$ / \mathrm{kW})\end{array}$ & $\begin{array}{l}\text { Electricity } \\
\text { Price } \\
(\$ / \mathrm{kWh})\end{array}$ \\
\hline $\begin{array}{l}\text { SUMMER } \\
\text { May-September }\end{array}$ & $\begin{array}{l}\text { On peak } \\
10: 00-17: 59\end{array}$ & 9.00 & .21262 \\
\cline { 2 - 4 } & $\begin{array}{l}\text { Mid } \\
5: 00-9: 59,18: 00-21: 59\end{array}$ & 5.78 & .11851 \\
\cline { 2 - 4 } & $\begin{array}{l}\text { Off peak } \\
0: 00-4: 59,22: 00-23: 59\end{array}$ & 5.78 & .07442 \\
\hline $\begin{array}{l}\text { WINTER } \\
\text { January-April } \\
\text { October-December }\end{array}$ & $\begin{array}{l}\text { Mid } \\
5: 00-21: 59\end{array}$ & 5.78 & .11281 \\
\cline { 2 - 4 } & $\begin{array}{l}\text { Off Peak } \\
0: 00-4: 59,22: 00-23: 59\end{array}$ & 5.78 & .06995 \\
\hline
\end{tabular}

